\title{
Solidification and compositional convection of a ternary alloy
}

\author{
By ANDREW F. THOMPSON $\dagger$, HERBERT E. HUPPERT, \\ M. GRAE WORSTER AND ANNELI AITTA \\ Institute of Theoretical Geophysics, Department of Applied Mathematics and Theoretical Physics, \\ University of Cambridge, Wilberforce Road, Cambridge CB3 0WA, UK
}

(Received 14 March 2003 and in revised form 30 June 2003)

We present the results of an experimental study on the solidification of aqueous solutions of potassium nitrate and sodium nitrate cooled from below. Upon cooling, two distinct mushy layers form, primary and cotectic, separated by an approximately planar horizontal interface. A density reversal between the two mushes causes the residual liquid in the upper, primary mush to be more buoyant than the melt overlying it, while the cotectic mush is compositionally stable. The unstable concentration gradient between the melt and primary mush causes convection that keeps the melt well-mixed and reduces the concentration gradient to zero after a finite time. At this point, the cotectic mush overtakes the primary mush and a transition from a convective regime to a diffusive regime occurs. Our measurements show that this transition is rapid and alters the growth rate of the single (cotectic) mush layer that remains. Concentration measurements taken from within the melt during convection and from within the mush during the diffusive regime show good agreement with the concentration evolution predicted by use of the equilibrium ternary phase diagram. We describe a global conservation model for solidification of a ternary alloy in this regime. Predictions from our model forced with empirical data for the heat and solute fluxes are in good agreement with the measured data for the interface positions of the two mushy layers. We also discuss how solid fractions vary with different melt concentrations in a non-convecting alloy and examine the influence of vertical solute transport in the convecting case. The identification of a density reversal in the solidification of a ternary alloy begins to address the complexities in solidification processes of multi-component alloys.

\section{Introduction}

The formation of solids by cooling a liquid melt is an integral part of many natural and industrial processes. Many of these solidification processes also generate fluid flows that are effective means of heat and mass transport and significantly influence the structure and growth rate of the solid phase. These fluid motions occur in liquid alloys owing to thermal convection caused by cooling the melt or to compositional convection caused by the removal of one or more components from the melt to form the solid phase. Preferential incorporation of components into the solid and rejection of others into the melt can also lead to constitutional supercooling, which

$\dagger$ Present address: Scripps Institution of Oceanography, University of California San Diego, La Jolla, CA 92037, USA. 
gives rise to the formation of one or more mushy layers between the melt and solid phases (Mullins \& Sekerka 1964; Worster 2000). Processes where fluid flows play an important role in solidification include metal castings formed from molten alloys (Copley et al. 1970), the formation of sea ice (Wettlaufer, Worster \& Huppert 1997, 2000) and the freezing of magma chambers (Huppert \& Sparks 1984).

A number of different fluid flows can develop even in the solidification of a simple binary alloy (Huppert 1990). As the number of components in an alloy increases, the range of possible behaviour increases as well. More specifically, a ternary alloy exhibits dynamics, such as density reversals, not observed in binary systems. A density reversal in an alloy occurs when the partial solidification of a component, previously in a liquid phase, causes the density gradient in the liquid to reverse sign. For example, Huppert \& Sparks (1980) discussed the convective regimes during the formation of Mid Ocean Ridge Basalts (MORBs) which experience a density reversal as first olivine and then plagioclase are solidified out of the multi-component magma.

The potential for different convective behaviours of a ternary alloy can be identified with the use of a ternary phase diagram (Aitta, Huppert \& Worster 2001a). An alloy's phase diagram indicates the phases present at local thermodynamic equilibrium for a given concentration and temperature. A full description of ternary phase diagrams can be found in West (1982), which also includes more complex systems than the one described here.

The phase diagram is important because it determines the order in which each component of an alloy solidifies along the liquid line of descent. A plan view of a simple ternary phase diagram with a single ternary eutectic point and a typical liquid line of descent is shown in figure 1. A ternary alloy initially in a liquid phase cools until it reaches the liquidus point. The liquidus point lies on the concentration-temperature surface, where a single component first begins to solidify. The first component forms a solid crystal matrix bathed in residual liquid in a region called the primary mush. An important property of mushy layers is that to a good approximation they conform to local thermodynamic equilibrium so that temperature and concentration are coupled by a single relationship (Worster 2000). Within this mushy layer, the residual liquid becomes enriched in the other two components which remain in the same ratio. This evolution of concentration and the associated temperature in the residual liquid occurs along the tie line, which connects the liquidus point to the corner of the phase diagram representing the pure solidifying component and intersects one of three cotectic curves indicated by the dashed lines in figure 1 . These cotectic curves represent the range of concentration and temperature at which two components are in a solid phase coexisting in equilibrium with one another and the remaining liquid. Further cooling leads to the formation of a cotectic mush, which has a crystal matrix of two solid components bathed in residual liquid, and causes the concentration and temperature of the residual liquid to evolve along the cotectic curve. Eventually the system will reach its eutectic point, the only combination of concentration and temperature at which all three solid components and a liquid phase can co-exist in equilibrium. Cooling below the eutectic point leads to the formation of a eutectic composite solid.

Aitta, Huppert \& Worster (2001b, herein referred to as AHW) initiated an experimental study of ternary alloys in a laboratory setting by cooling from below a simple alloy of two salts dissolved in water. Temperature and concentration measurements were made at different heights within the tank and at various times, and the positions of the melt-mush interface and the mush-solid interface were tracked over time. In that study, the initial concentrations of the alloy were chosen 


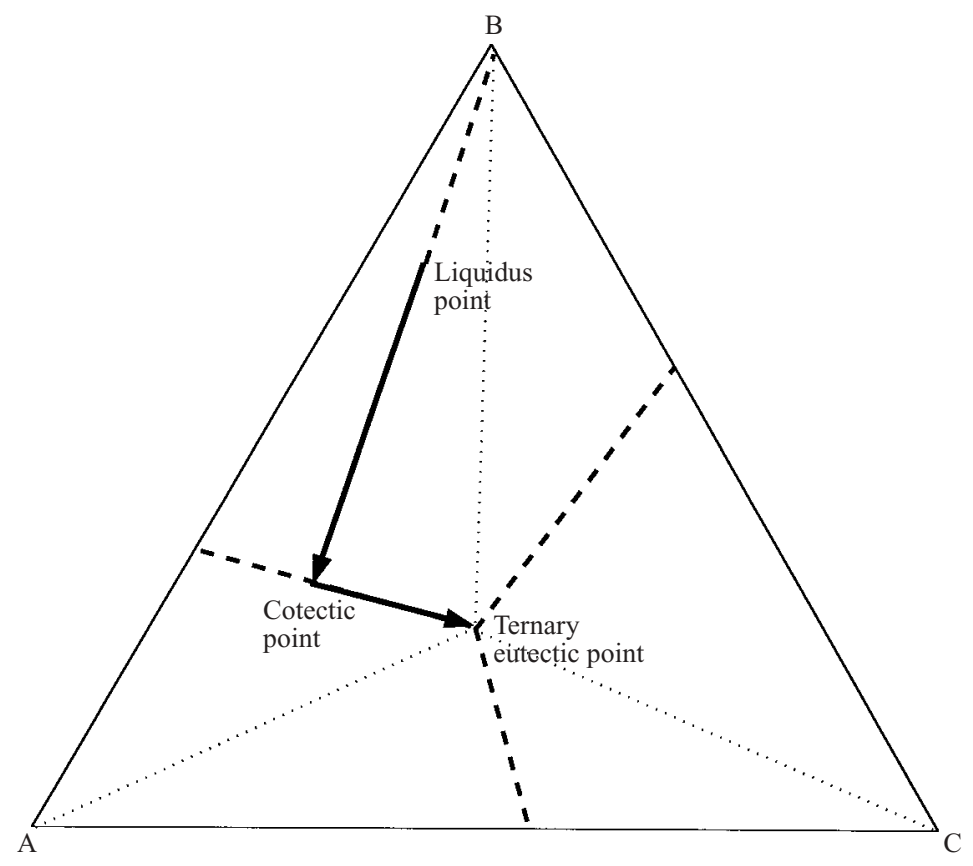

FIGURE 1. Plan view of a simple ternary phase diagram depicting a typical liquid line of descent. In this diagram, the three fields are separated by the cotectic curves (dashed lines) and temperature is measured along the vertical axis out of the page. Here the liquidus point falls in the field associated with B, indicating that it is component $\mathrm{B}$ that forms a solid phase in the primary mush. The liquid line of descent (bold line) shows that the temperature and concentration evolve along the tie line until it reaches the cotectic point. At this point a cotectic mush forms composed of solid A and B and residual liquid. Further cooling causes the temperature and concentration of the residual liquid in the cotectic mush to evolve along the cotectic curve until the residual liquid reaches eutectic concentrations. Cooling below the eutectic temperature at these concentrations leads to the formation of a eutectic composite solid. Similar liquid lines of descent occur in each of the three fields, but the stratification of the residual liquid in these mushy layers will differ depending on which components are incorporated into a solid phase.

so that the residual liquid in the mushy layers was denser than the fluid overlying it. The compositional and thermal fields of the alloy were stably stratified at all times, and convection did not play a role in the growth dynamics. Results from these experiments showed that the growth of the mushy layers and the composite solid were diffusion-limited and the interface positions of these layers grew at a rate proportional to the square root of time after some initial transients, possibly related to a nucleation delay. The interface between the primary and cotectic mushes was also inferred through concentration measurements within the mushy layers. In our experiments this boundary was measured explicitly through visual observations.

More recently Bloomfield \& Huppert (2003) analysed two regimes of an aqueous ternary alloy cooled from the side. In the first regime, heavy fluid was released upon solidification and both the thermal and compositional boundary layers flowed to the base of the tank. In the second regime, the residual liquid was relatively light and the thermal and compositional boundary layers were opposed. A wide range of convective behaviours was observable in this case, including uni-directional 
downflow, counterflow and mixed upflow. Density reversals were also observed, so that over time the rejected fluid evolved from relatively light to relatively heavy and eventually the dynamics of the first regime were recovered. Our experimental study investigated the solidification of an aqueous ternary alloy from a lower horizontal boundary which incorporated both compositional convection and a density reversal. This density reversal was transient, however, since the layer of light fluid mixed with the melt above it and eventually disappeared. At this point, as in Bloomfield \& Huppert (2003), the dynamics reverted to a simpler case, namely the diffusion-limited growth studied by AHW.

We begin by describing a series of experiments exploring a compositionally unstable regime of a ternary alloy and presenting our observations and results. In $\S 3$ we develop a simple global conservation model to describe the experiments. The global conservation model is an extension of the binary model developed by Huppert \& Worster (1985) and modified to include convection by Kerr et al. (1990a). In $\S 4$ we consider the special case in which convection is absent and investigate the effects of varying initial concentrations and the base temperature on the solid fractions. We discuss the full model including convection in $\S 5$, and describe how the interface positions of the two mushy layers and the solid fractions evolve with time. In that section we also compare the positions of the two mushy layers with the experimental observations, and discuss a correction term to take into account the heat flux between the laboratory and the experimental tank. We summarize our main results and conclusions in $\S 6$.

\section{Laboratory experiments}

\subsection{Methods}

The aim of our laboratory experiments was to explore the behaviour of a ternary alloy cooled from below in a regime where compositional convection affects the solidification process. We used the ternary alloy selected by AHW consisting of two salts, potassium nitrate $\left(\mathrm{KNO}_{3}\right)$ and sodium nitrate $\left(\mathrm{NaNO}_{3}\right)$, dissolved in the third component, water. This alloy was chosen because it is transparent, which enables visual observation, and because the liquidus and eutectic temperatures could be readily reached with typical laboratory equipment. This alloy also conforms to a simple phase diagram without any peritectic points near the ternary eutectic point, and the concentration of $\mathrm{KNO}_{3}$ and $\mathrm{NaNO}_{3}$ in water could be accurately measured using a Varian SpectrAA flame atomic absorption spectrometer (AAS). The solidification field of interest for the current set of experiments was the $\mathrm{KNO}_{3}$ field. With the conditions explored in the experiments, $\mathrm{KNO}_{3}$ solidified in the primary mush and $\mathrm{KNO}_{3}$ and $\mathrm{H}_{2} \mathrm{O}$ solidified in the cotectic mush. The liquidus surface was assumed to be planar (an approximation that will be discussed further in the following section) and the points defining this surface appear in table 1.

The experiments were conducted in a rectangular Perspex tank with internal horizontal dimensions $20 \mathrm{~cm} \times 20 \mathrm{~cm}$, which was filled with solution to a depth of approximately $35 \mathrm{~cm}$. The walls were $1.3 \mathrm{~cm}$ thick and the top was covered with a Perspex lid $1.5 \mathrm{~cm}$ thick. The base consisted of a $2.5 \mathrm{~cm}$ thick brass plate that had been milled to allow coolant to flow through it and cool the plate evenly. The whole system was then insulated with a layer of expanded polystyrene whose thickness was $5 \mathrm{~cm}$ around the sidewalls and above the lid and $10 \mathrm{~cm}$ below the baseplate. The initial concentrations were decided upon before each experiment and commercial salts with less than $2 \%$ impurities (as stated on the packaging) were measured out 


$\begin{array}{ccccc}\text { Phase diagram point } & \text { Temperature }\left[{ }^{\circ} \mathrm{C}\right] & \mathrm{KNO}_{3}[\mathrm{wt} \%] & \mathrm{H}_{2} \mathrm{O}[\mathrm{wt} \%] & \mathrm{NaNO}_{3}[\mathrm{wt} \%] \\ \text { Ternary eutectic } & -19.0 & 5.4 & 59.1 & 35.5 \\ \text { Binary eutectic } & -2.84 & 9.0 & 91.0 & 0 \\ \left(\mathrm{KNO}_{3}-\mathrm{H}_{2} \mathrm{O}\right) & & & & 0 \\ \text { Saturation point } & 25.0 & 27.7 & 72.3 & 0\end{array}$

TABLE 1. List of values from the phase diagram of the $\mathrm{H}_{2} \mathrm{O}-\mathrm{KNO}_{3}-\mathrm{NaNO}_{3}$ alloy used to define the liquidus surface. All values are taken from AHW with the exception of the saturation value of $\mathrm{KNO}_{3}$ in water, which was taken from Lide (1997). The concentration values for the binary and ternary eutectic points are based on the updated cotectic curve between $\mathrm{KNO}_{3}$ and $\mathrm{H}_{2} \mathrm{O}$ reported by AHW. The saturation point is used as the third point because the experiments occur in a localized region of the phase diagram near the $\mathrm{KNO}_{3}-\mathrm{H}_{2} \mathrm{O}$ cotectic curve, far from the melting point of pure $\mathrm{KNO}_{3}$ (see $\S 3$ for further discussion).

to specifications and dissolved in de-ionized water. The dissolution of these salts is endothermic. Solutions were prepared and left overnight so that they would return to room temperature before the start of each experiment. Before each experiment the solution was filtered and samples were taken in order to verify that the proposed initial conditions were correct.

The system was cooled using a Haake cooling unit that was connected to the brass plate by plastic tubing. The cooling unit contained a reservoir of ethylene glycol (anti-freeze) mixed with 50\% water, pumped around a loop in order to maintain the reservoir at a specified temperature. The cooling unit was allowed to run through a bypass circuit overnight in order to bring the coolant to an initial low temperature (approximately $-27^{\circ} \mathrm{C}$ ). At the start of the experiment, the coolant was allowed to pass into the baseplate at time designated $t=0$. In the experiments conducted by AHW, the baseplate was maintained at a constant temperature below the eutectic temperature by manually adjusting the cooling unit. In the current experiments, the cooling unit was in competition with warm liquid brought near the baseplate by convection. Because of this, temperatures below eutectic could only be reached in times comparable to the entire period over which convection occurred. Hence two separate methods for specifying the base temperature were used. The first method kept the cooler working at full capacity and allowed the baseplate to cool down gradually to a constant temperature below the eutectic temperature. During the second method, the cooler was manually adjusted to keep the temperature of the baseplate constant throughout the experiment. After approximately two hours, the temperature of the baseplate could be kept constant to within $\pm 0.05^{\circ} \mathrm{C}$. With the second method, it was possible to achieve a baseplate temperature less than the cotectic temperatures, but not less than the eutectic temperature.

The temperature of the baseplate and the temperature inside the tank were measured using glass-bead thermistors that had a temperature range of $-55^{\circ} \mathrm{C}$ to $125^{\circ} \mathrm{C}$. One thermistor was embedded in the middle of the baseplate near the upper surface. Seven other thermistors were positioned at 1, 2.5, 4, 8, 12, 20 and $30 \mathrm{~cm}$ above the baseplate. These thermistors were attached to stainless steel rods inserted horizontally into the tank such that the glass bead was approximately $7 \mathrm{~cm}$ from the wall through which the rod was inserted and equidistant from the next two closest walls. Each glass bead contained a small thermistor whose resistance is a function of temperature with a nominal resistance of $1 \mathrm{k} \Omega$ at $25^{\circ} \mathrm{C}$. These were then connected to a computer via a bridge and an $\mathrm{A}$ to $\mathrm{D}$ board. The computer had the proper calibrations to 
compute the temperature from the resistances. The computer recorded temperature automatically at specified intervals, which could be adjusted during the course of the experiment.

Samples of the liquid were removed at various times and at various heights using a long thin syringe inserted in a small opening at the top of the tank. While the system was convecting, the mushy layers were flush against the sides of the tank so samples were only removed from the liquid region above the mushy layers. As will be discussed in $\S 2.2$, convection eventually stopped, and the mushy layer formed a humped shape that allowed samples to be removed from the side of the tank below the melt-mush interface. To remove samples from this region, the lid of the tank had to be removed. This sampling lasted no longer than one or two minutes. Each sample was then diluted 1:500 by volume so that accurate readings could be obtained using the AAS. A set of samples with known concentrations for each salt were used as standards to calibrate the AAS. The AAS used flame emission to determine the concentration of a given element in water (potassium $\mathrm{K}$ and sodium $\mathrm{Na}$ for these experiments), given in units of $\mu \mathrm{g} \mathrm{cm}^{-3}$. The calibration, which was highly dependent on the strength and stability of the flame, was checked after every ten samples. The concentrations were then converted to a volume percentage by multiplying by the dilution factor 500, a factor of $10^{6}$ (to convert from $\mu \mathrm{g} \mathrm{cm}^{-3}$ to $\mathrm{g} \mathrm{cm}^{-3}$ ), and the molecular weight of the salt divided by the atomic weight of the element. Then the weight percent was determined by dividing by the density of the liquid. The density was determined using the function,

$$
\rho=1+a_{1} N+b_{1} K+a_{2} N^{2}+b_{2} K^{2}+c N K,
$$

where $N$ and $K$ are weight percentages of the salts $\mathrm{NaNO}_{3}$ and $\mathrm{KNO}_{3}$ respectively. The values of the coefficients in (2.1) are $a_{1}=0.006387, a_{2}=-6.728 \times 10^{-6}, b_{1}=$ $0.005898, b_{2}=-2.227 \times 10^{-6}$, and $c=2.083 \times 10^{-4}$ as given in AHW. By using the standard solutions, it was determined that the AAS provided accurate concentration readings to within $\pm 0.2 \mathrm{wt} \%$.

Other measurements were made by simple observational techniques. The height of the primary and cotectic mushes and the eutectic solid were measured using a ruler and looking through the side of the tank. The interface between the liquid and primary mush was well-defined at all times. The interface between the primary and cotectic mushes could be distinguished throughout most of the experiment to within $\pm 1 \mathrm{~mm}$ by shining a strong, focused LED penlight through the side of the tank. This interface became more difficult to observe close to the transition from a convective to diffusion-controlled regime. In experiments where a eutectic solid formed, the solid layer was bright white, and the interface between the solid, eutectic layer and the cotectic mushy layer was well-defined. The strength and structure of the convection was visualized with standard shadowgraph techniques using a projector and tracing paper.

\subsection{Observations}

Table 2 summarizes the experiments conducted for this study. The height and time at which the cotectic front overtook the primary front (as described below) are labelled $h^{*}$ and $t^{*}$.

Crystal formation began approximately one minute after the coolant entered the baseplate. The crystals initially had a small fibre-like structure and formed in one or two locations before spreading over the entire baseplate. The baseplate was completely covered with crystals within the first two minutes of the experiment. Evidence of the 


\begin{tabular}{|c|c|c|c|c|c|c|c|c|}
\hline \multirow[b]{2}{*}{ Expt } & \multicolumn{2}{|c|}{$\begin{array}{c}\text { Initial conc. } \\
{[\mathrm{wt} \%]}\end{array}$} & \multirow{2}{*}{$\begin{array}{c}\text { Base } \\
\text { condition }\end{array}$} & \multirow{2}{*}{$\begin{array}{c}\text { Minimum } \\
\text { base temp. } \\
{\left[{ }^{\circ} \mathrm{C}\right]}\end{array}$} & \multirow{2}{*}{$\begin{array}{l}\text { Eutectic } \\
\text { solid }\end{array}$} & \multirow{2}{*}{$\begin{array}{c}\text { Total } \\
\text { duration } \\
{[\mathrm{h}]}\end{array}$} & \multirow{2}{*}{$\begin{array}{l}t^{*} \\
{[\mathrm{~h}]}\end{array}$} & \multirow{2}{*}{$\begin{array}{c}h^{*} \\
{[\mathrm{~cm}]}\end{array}$} \\
\hline & $\mathrm{H}_{2} \mathrm{O}$ & $\mathrm{NaNO}_{3}$ & & & & & & \\
\hline 1 & 78 & 10 & constant & -17.2 & no & 58 & 7.5 & 2.3 \\
\hline 2 & 78 & 10 & cooled & -27.2 & yes & 46 & 6.5 & 2.5 \\
\hline 3 & 75.9 & 9.1 & cooled & -23.6 & yes & 71 & 10 & 3.4 \\
\hline 4 & 76.8 & 3.0 & cooled & -25.8 & no & 100 & 19 & 4.8 \\
\hline 5 & 75.9 & 9.7 & cooled & -25.7 & yes & 96 & 16 & 3.5 \\
\hline 6 & 78.0 & 7.2 & cooled & -25.7 & yes & 76 & 16 & 4.0 \\
\hline 7 & 72.6 & 15.0 & constant & -14.0 & no & 105 & 30 & 3.3 \\
\hline 8 & 75 & 7 & constant & -14.8 & no & 105 & 35 & 4.4 \\
\hline
\end{tabular}

TABLE 2. Experimental parameters. The base condition refers to the specification of temperature at the baseplate, either gradually cooled below the eutectic temperature or maintained at a constant temperature throughout the experiment; $t^{*}$ and $h^{*}$ are respectively the time and height at which the cotectic mush overtook the primary mush; $t^{*}$ is also the duration of convection in each experiment.

development of strong convection was visible within five minutes of the start of the experiment. This initial convection was sufficiently strong to keep the fluid in the tank well-mixed. In all the experiments, convection appeared to occur initially in the form of salt fingers for approximately ten minutes. The convection then became much more vigorous, which lasted for approximately half the period of total convecting time, after which it began to decay again into fingering convection. There was no evidence of chimneys in the mushy layer during these experiments. This could be due to what appeared to be wide spacing between crystals in the primary mush layer, which could allow relatively less dense fluid to rise without dissolving a significant number of crystals, the typical mechanism for chimney formation (Worster 2000). After 1 to 2 hours, the crystals looked like short hairs and were finer and thinner than those that first covered the baseplate. With this change the interface at the top of the primary mush layer became spiky with some crystals protruding above the flat interface. In experiments where the baseplate was allowed to cool below the eutectic temperature and convection was strong, some of these fine crystals broke off from the solid matrix and were carried into the liquid layer by convective fluid motion. Similar observations were made in experiments by Sarazin \& Hellawell (1992) where chimney formation was reported. Unlike the mushy layers in the diffusion-limited growth regime described by AHW, which were hump-shaped with open fluid between the mush and side walls over most of their height, the mush here remained flush against the side walls of the tank.

After the first few hours, the top of the cotectic layer began to catch up slowly with the top of the primary mush layer. After approximately half the convecting time the crystals still had a hair-like structure, but had become thicker. During this period the convection continued steadily. In the experiments where the baseplate was continuously cooled, convection started to weaken after approximately 12 to 14 hours. In the case where the baseplate was kept at a constant temperature (and at a higher temperature than the other set of experiments), convection started to weaken after approximately 23 hours. The weakening of convection corresponded to the thinning of the primary mush layer and the establishment of fingering convection, which eventually led to the entire depth of the tank no longer being well-mixed. As 
the primary mush layer became very thin, the crystal structure at the melt-mush interface again appeared to change as the hair-like crystals seemed to disappear or be dissolved. Once the cotectic layer had overtaken the primary mush, convection ceased completely. Shortly after this transition, the crystal structure was replaced by a more solid-looking mush that was corrugated. The process of convection weakening and then ceasing happened more abruptly in the experiments where the baseplate was allowed to cool below the eutectic temperature. In general, though, the transition between a convecting state and a diffusion-controlled state was rapid compared to the length of time during which convection occurred.

At the height where the cotectic mush overtook the primary mush, a visible horizontal interface remained behind as the mush continued to grow. This interface was identifiable by a change in crystal structure or solid fraction and remained visible and at a constant height as the experiment progressed. As the mushy layer continued to grow into the liquid, a space formed between the sides of the tank and the mushy layer. This space, which increased with height and grew to a width of approximately $2 \mathrm{~cm}$, was similar to the gap observed by AHW in the diffusion-controlled, nonconvecting regime of this alloy. This gap is most likely to have been caused by heat gains from the laboratory.

A eutectic solid layer was observed in four of the experiments where the baseplate was allowed to cool below the eutectic temperature. It formed well after the baseplate had been cooled below the eutectic temperature. This is similar to the long nucleation times for the eutectic solid observed by AHW. In the experiments where a eutectic solid formed, the time at which this layer first became visible coincided with the time that convection ceased completely. Eutectic solid was not observed in one experiment where the baseplate temperature was below the eutectic temperature: the initial concentration of $\mathrm{NaNO}_{3}$ was low in this experiment, and would have had to increase by an order of magnitude to reach its eutectic concentration. This may have either led to longer delays in the nucleation of the solid, or made it difficult for the system to conform to equilibrium dynamics at low temperatures.

\subsection{Measurements}

\subsubsection{Temperatures}

The temperatures measured in experiment 4 , with a continuously cooled baseplate, are shown in figure 2 as a function of time. A base temperature of $-13^{\circ} \mathrm{C}$ was achieved after 20 minutes, at which time it rose abruptly before decreasing again at a slower rate until convection stopped. This short rise in temperature indicates the nucleation of the cotectic mush, since the liquid must be supercooled before the layer can form. The slow change in baseplate temperature suggests that during convection there was competition between warm liquid brought close to the baseplate by convection and the coolant within the baseplate. During convection the temperature in the melt was essentially uniform, indicating that this region was well-mixed. Thermistor traces decreased from this uniform temperature as each thermistor entered the mush. There was also a discontinuity in the gradient of the baseplate temperature in all experiments in which a eutectic solid layer formed. This occurred as the baseplate reached its minimum temperature, and may have been caused by the release of latent heat during the nucleation of the eutectic solid as well as by the termination of convection. After convection ended, the temperature near the top of the tank increased due to heating from the laboratory, and the temperature profile suggests that the tank had become thermally stratified. 


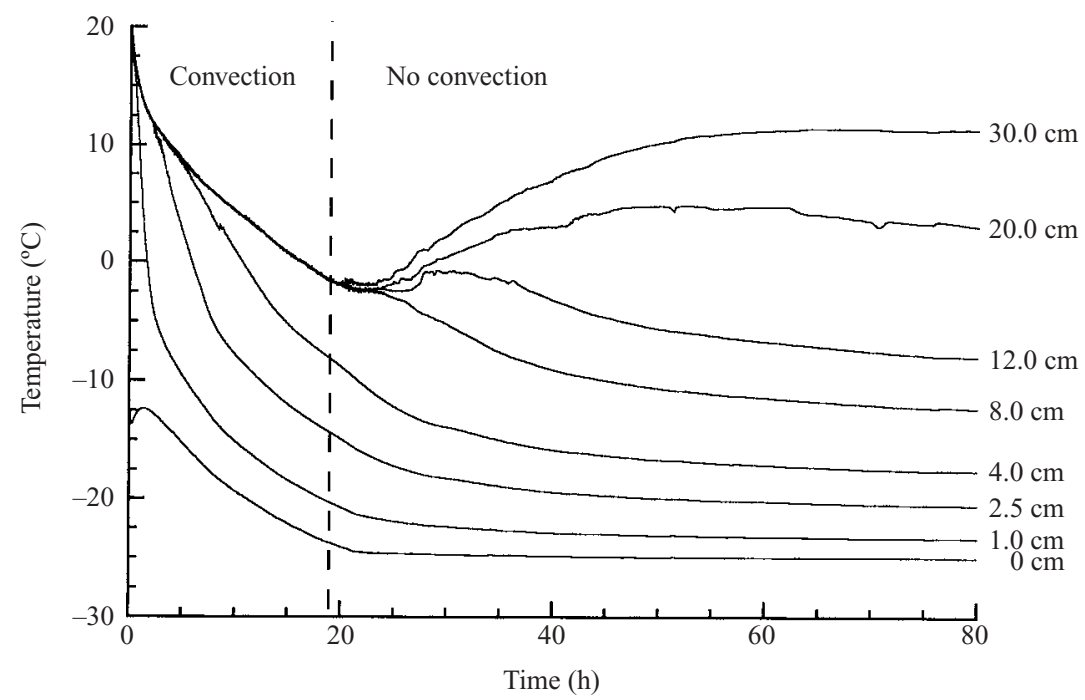

FiguRE 2. Temperature traces from all eight thermistors as a function of time from experiment 4 with a continuously cooled base condition. The dashed line marks the end of convection, at approximately 19 hours.

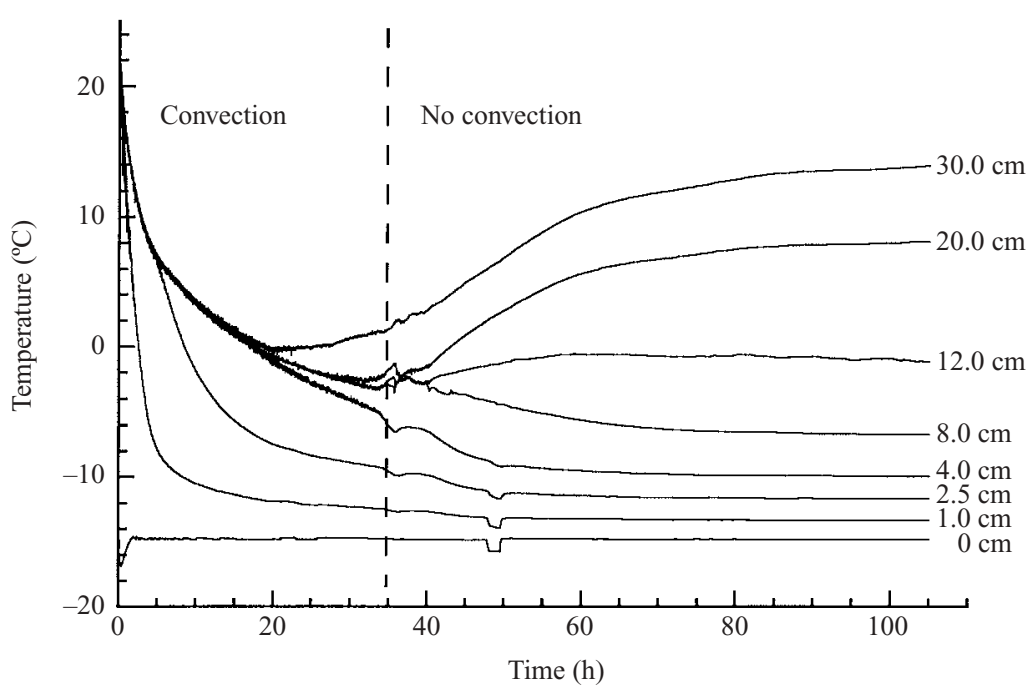

FIGURE 3. Temperature traces from all eight thermistors as a function of time from experiment 8 with a constant base temperature condition. The dashed line marks the end of convection, at approximately 35 hours. The drop in temperature at the baseplate around 48 hours was due to personal error.

The temperature traces from experiment 8 are presented in figure 3 . The baseplate was quickly brought to a temperature of $-16.8^{\circ} \mathrm{C}$, and after two hours it was possible to maintain the temperature of the baseplate steady at $-14.75 \pm 0.05^{\circ} \mathrm{C}$. The rise in temperature during this time was due to the large latent heat release upon nucleation of the cotectic mush. The drop in baseplate temperature at approximately 48 hours was due to operator error with the control panel on the cooler, but it is interesting 


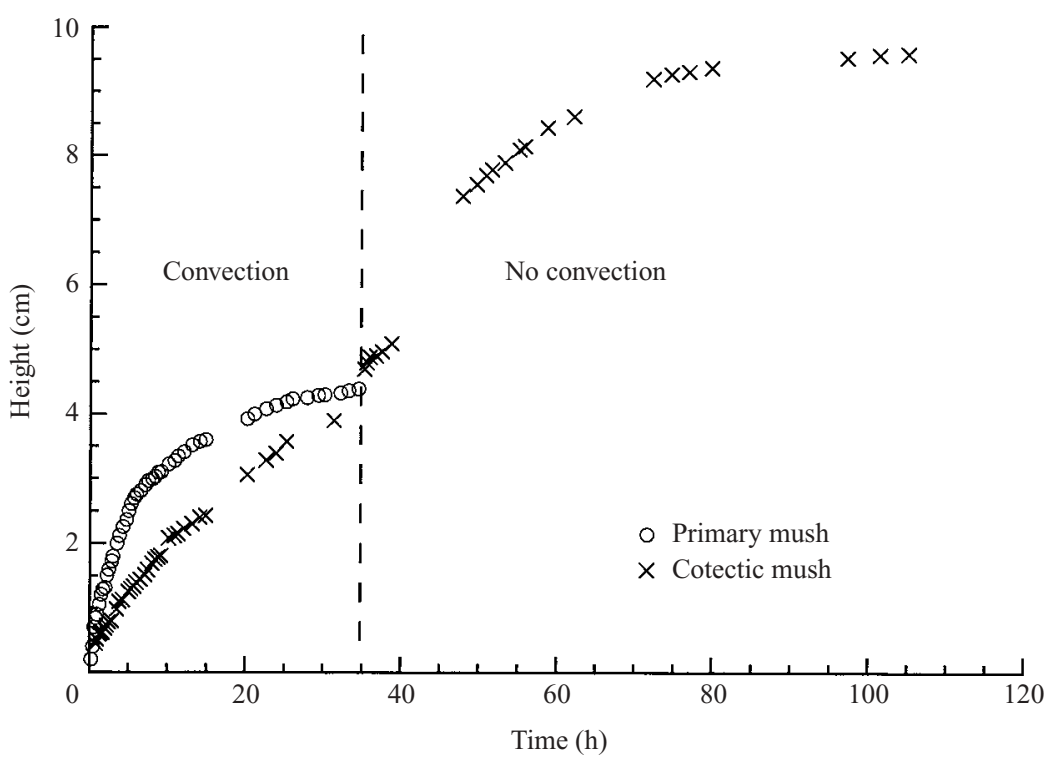

FIGURE 4. The height of the primary and cotectic mushes as a function of time from experiment 8 . The dashed line marks the end of convection, at approximately 35 hours.

to see how the signal propagated through the mush. The tank was well mixed throughout most of the convective regime, and became stratified after the transition to the diffusive regime. The fluctuations in temperature at some of the thermistors at approximately 34 hours was a feature seen in all of the constant-base-temperature experiments, but none of the continuously cooled experiments. These fluctuations coincided with the end of the convecting regime, and seemed to propagate through the mushy layer. No reason for this feature is obvious at present.

\subsubsection{Heights}

The evolution of the heights of the primary and cotectic mushes from experiment 8 is shown in figure 4 . This plot shows the cotectic mush overtaking the primary mush, and altering the growth rate of the remaining mushy layer. After the cotectic mush overtook the primary mush, only the cotectic mushy layer remained, and the growth was diffusion-limited. In experiments in which a eutectic solid formed, initiation of this layer tended to coincide with the cotectic layer overtaking the primary layer, when convection in the system ceased. Growth of the cotectic mush and eutectic solid after convection may not be self-similar due to (weak) effects from the finite size of the tank.

Figure $5(a)$ is a plot of the height of the primary mush layer against time with $\log -\log$ axes. Experiments with constant baseplate temperatures are shown with solid symbols and experiments with continuously cooled baseplate conditions are shown with open symbols. Both time and height values have been non-dimensionalized using the time $t^{*}$ and height $h^{*}$ at which the cotectic mush overtook the primary mush. In a non-convecting regime, the growth of the primary mush is self-similar, following the relationship $h \sim t^{1 / 2}$. Here the open symbols follow this relationship approximately, but this may represent a balance between the convective heat flux, which inhibited growth, and the decreasing baseplate temperature, which increased the growth rate. Experiments with closed symbols follow the $h \sim t^{1 / 2}$ relationship over the decade, 

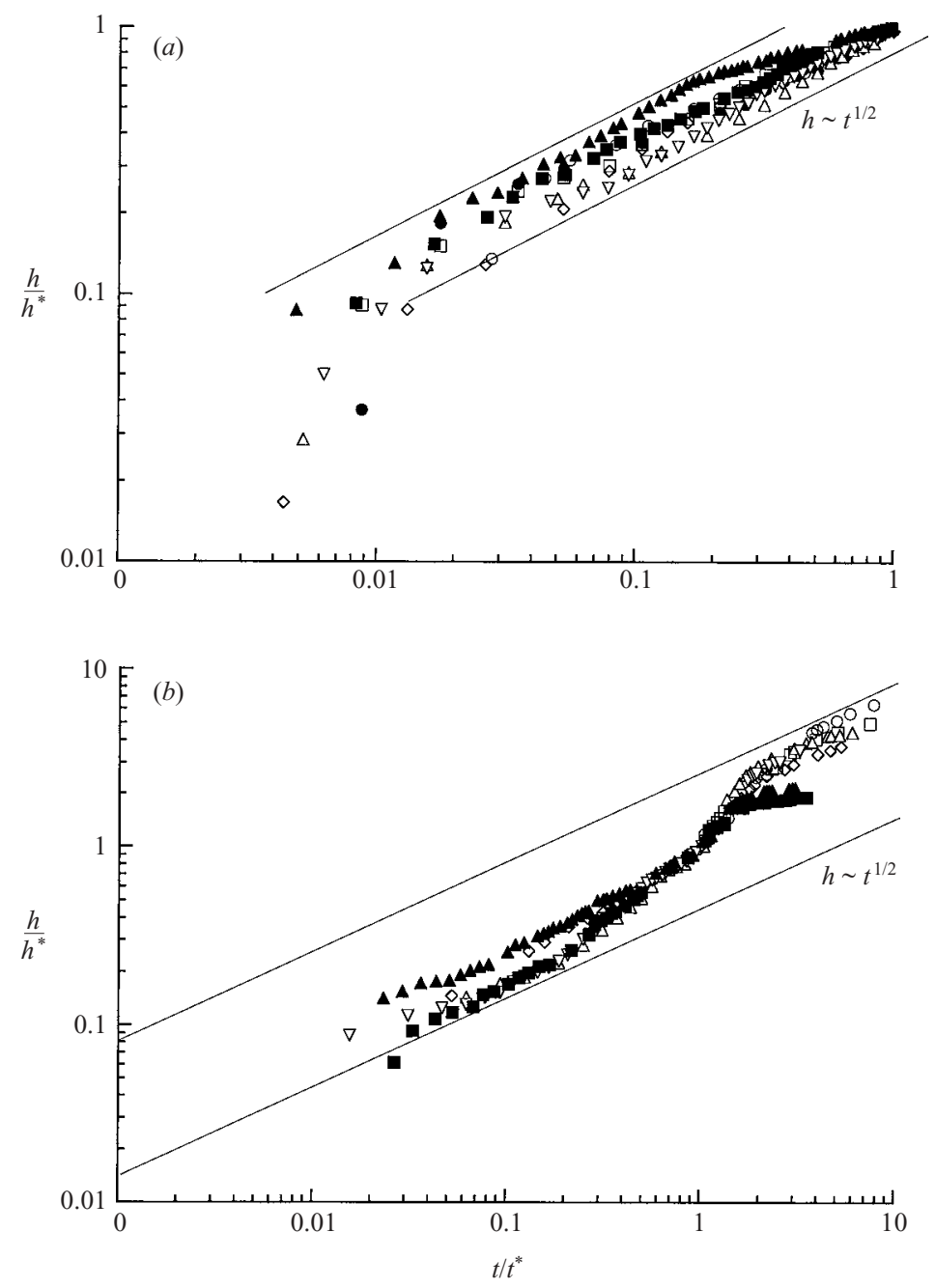

FIGURE 5. The non-dimensionalized height of $(a)$ the primary mush and $(b)$ the cotectic mush as functions of non-dimensionalized time in each experiment. Values are non-dimensionalized with the time $t^{*}$ and height $h^{*}$ at which the cotectic mush overtook the primary mush. Open symbols represent a continuously cooled baseplate condition and solid symbols represent a constant baseplate temperature condition.

$0.01<t / t^{*}<0.1$, but over the following decade the slope decreased. This suggests that at early times the effects of convection were small and the principal balance was between conduction and latent heat release, but at later times the convective heat flux limited the growth rate. At very early times the growth rates were influenced by transients associated with initial cooling.

Figure $5(b)$ shows the height of the cotectic layer as a function of time with $\log -$ $\log$ axes. Again the time and height are non-dimensionalized with $t^{*}$ and $h^{*}$, and solid symbols represent constant-base-temperature conditions while open symbols represent cooled base conditions. At early times the slopes of the curves are close to $1 / 2$, which suggests that convection initially had a small effect on the cotectic layer. Around $t / t^{*}=0.2$ the rate of growth of the cotectic mush increased in each 
experiment. This continued until the time at which the cotectic mush overtook the primary mush. At this point there was a transition back to a diffusion-limited growth regime. After convection ceased, the growth rate of the cotectic mush in experiments with a constant baseplate temperature was significantly smaller than in the cooledbase experiments, which may have been caused by higher levels of superheat in the former experiments. Since convection was generally stronger in experiments with a continuously cooled base, the liquid layer was kept well-mixed longer. Therefore, when convection ended there was less superheat in the melt to inhibit the growth rate. In experiments with a constant base temperature, convection weakened earlier and over a longer period of time allowing more superheat to develop before convection stopped completely.

\subsubsection{Concentrations}

The evolution of $\mathrm{KNO}_{3}$ concentration in the melt over time from experiment 6 is shown in figure $6(a)$. Samples were taken at heights of $4.5,20$ and $30 \mathrm{~cm}$ above the baseplate. As solid $\mathrm{KNO}_{3}$ was deposited in the primary mush and liquid depleted in this salt rose into the melt by compositional convection, the concentration of $\mathrm{KNO}_{3}$ in the melt decreased. This process continued until the cotectic layer, which was compositionally stable, overtook the primary mush. Then, by equilibrium thermodynamics, the concentrations at the melt-mush interface should have been at cotectic concentrations. Since the melt was well-mixed throughout most of the convection, concentrations should have been close to cotectic values in the melt as well. This is reflected in figure $6(a)$ as the concentration of $\mathrm{KNO}_{3}$ approached the cotectic concentration (dashed line) determined by a linear liquid line of descent. A similar evolution, but showing an enrichment in $\mathrm{H}_{2} \mathrm{O}$ is seen in figure $6(b)$ with the dashed line again indicating the cotectic concentration. The concentration of the solute $\mathrm{NaNO}_{3}$ changed very little because of the location of these experiments on the phase diagram, although the concentration did increase slightly due to its enrichment in the primary mush.

Figures $7(a)$ and $7(b)$ show the concentration of $\mathrm{KNO}_{3}$ and $\mathrm{H}_{2} \mathrm{O}$ in the melt in experiment 6 as a function of melt temperature during convection. The line connecting the liquidus point to the cotectic point indicates the linear tie line of this alloy. We expect the data to be at temperatures slightly higher than those specified by the tie line because temperature and concentration are not coupled in the melt whereas they are in the mushes. Since the evolution of concentration in the melt reflects the evolution of concentration in the primary mush, figure 7 seems to support the assumption that the liquidus curve is approximately linear. Concentration measurements taken from within the primary mush during convection would be necessary to examine this assumption formally.

Figures $8(a)$ and $8(b)$ show the concentration of $\mathrm{H}_{2} \mathrm{O}$ and $\mathrm{NaNO}_{3}$ in the melt and residual liquid in experiment 5 as a function of temperature at various times after convection had ended. The line connecting the binary eutectic point and the ternary eutectic point indicates the linear approximation to the cotectic curve. Data points below the dashed line, located at the cotectic temperature, indicate measurements made below the melt-mush interface, and should follow the cotectic curve in equilibrium. Agreement becomes worse as the temperature becomes lower. This could be due to a number of factors, including supercooling in the mush, the fact that samples were removed from the gap between the mush and the wall, and the difficulty of ensuring that a sample was withdrawn at the desired height. Similar deviations were found by Huppert \& Worster (1985). 

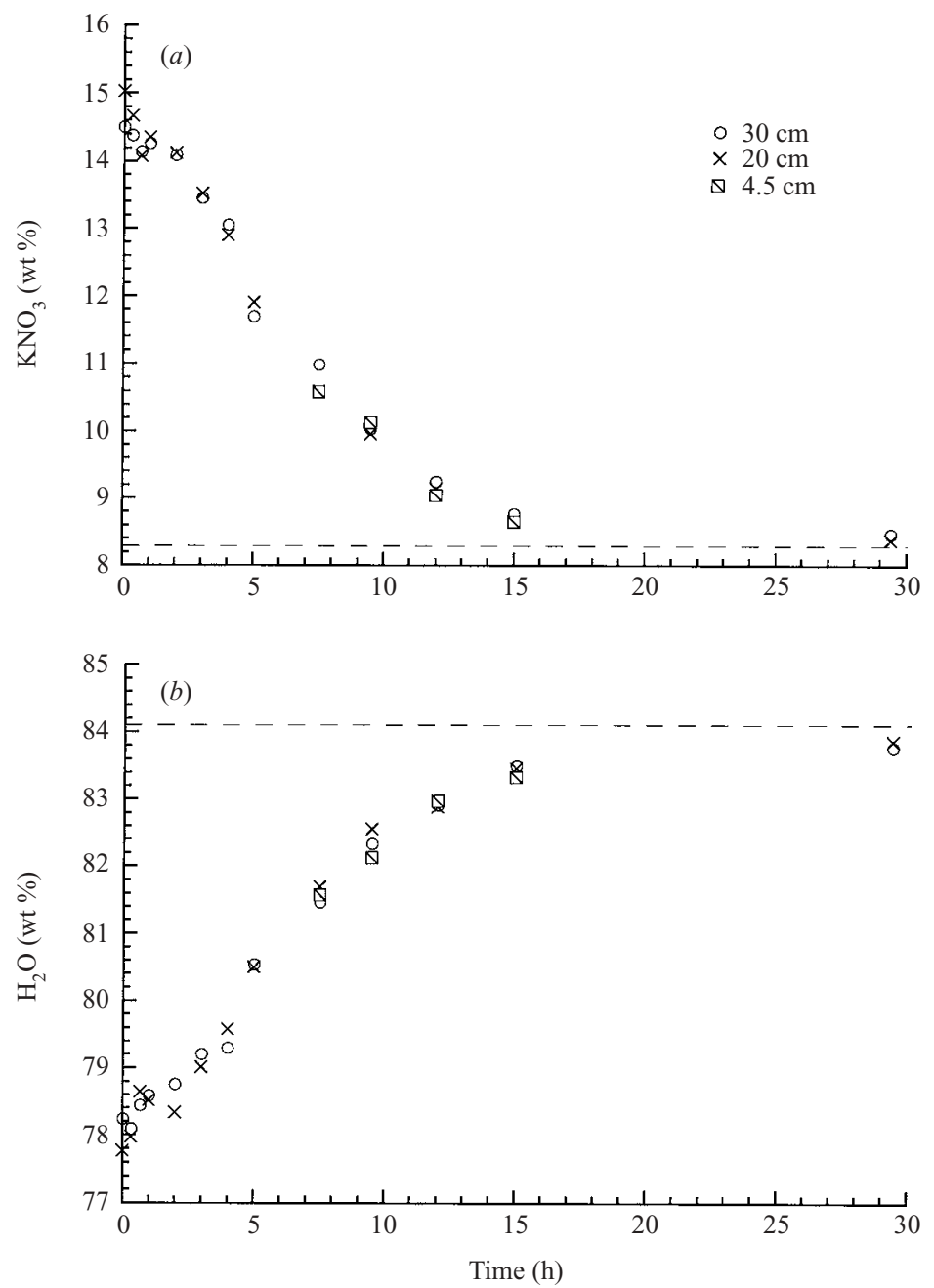

FiguRE 6. The concentrations of $(a) \mathrm{KNO}_{3}$ and $(b) \mathrm{H}_{2} \mathrm{O}$ in the melt in experiment 6 as functions of time during convection at heights of $4.5,20$ and $30 \mathrm{~cm}$ above the baseplate. The horizontal dashed line is the cotectic concentration as determined by linear liquid lines of descent, as discussed in $\S 2$, and the cotectic curve as reported by AHW. All cotectic concentrations shown in subsequent figures have been determined in a similar manner.

\subsubsection{Phase diagram and liquid line of descent}

In figure 9 the concentration of $\mathrm{H}_{2} \mathrm{O}$ and $\mathrm{NaNO}_{3}$ in the liquid at various times and various locations from four experiments $(4,5,6$ and 7$)$ are plotted in a plan view of the phase diagram. A much smaller number of concentration measurements were made in the other four experiments and so they are not included here. The concentration of $\mathrm{H}_{2} \mathrm{O}$ is shown on the horizontal axis since the experiments occurred in the $\mathrm{KNO}_{3}$ field and therefore the tie lines pass through $0 \% \mathrm{H}_{2} \mathrm{O}$ and $0 \% \mathrm{NaNO}_{3}$. The axes are presented orthogonally for easier interpretation. The dashed lines indicate the tie lines through the initial concentrations, represented by the large solid circles. The solid line is the $\mathrm{KNO}_{3}-\mathrm{H}_{2} \mathrm{O}$ cotectic curve based on the experiments of $\mathrm{AHW}$ in the $\mathrm{H}_{2} \mathrm{O}$ field. 

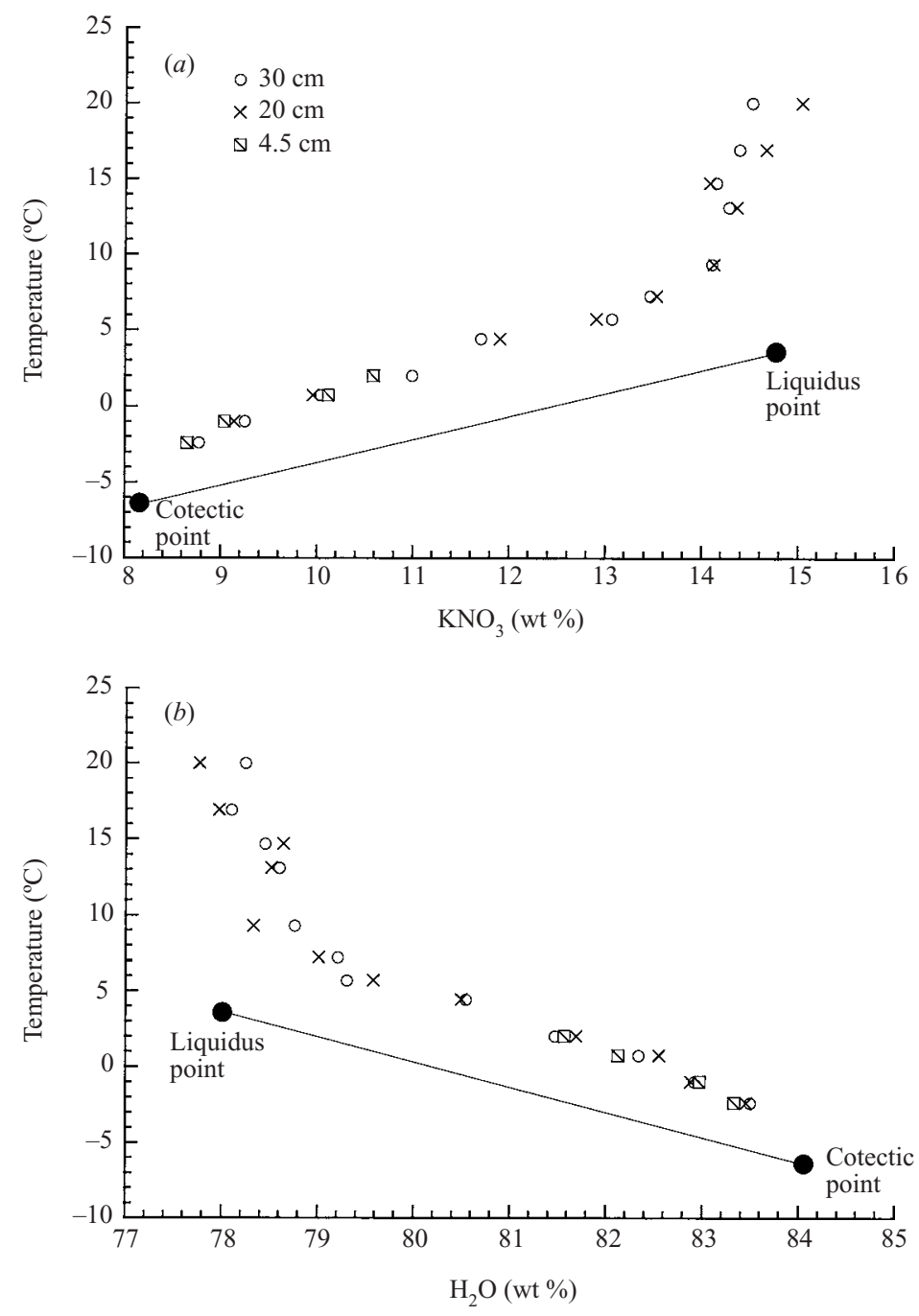

Figure 7. The concentrations of $(a) \mathrm{KNO}_{3}$ and $(b) \mathrm{H}_{2} \mathrm{O}$ in the melt in experiment 6 at various heights as functions of temperature during convection. The line indicates the linear tie line to the cotectic curve and represents the evolution of concentration and temperature in the residual liquid at the melt-mush interface. Temporal evolution moves from right to left in $(a)$ and from left to right in $(b)$.

We expect the data, in equilibrium, to follow a descent path as described in figure 1 . While figure 9 does not contain any information about time or location, evolution within the melt over time collapses onto the tie lines on the liquidus surface, while concentration measurements taken throughout the cotectic mush collapse onto the cotectic curve. In general, data evolve along the liquid line of descent with increasing time at a fixed height or with increasing depth below the melt-mush interface at a fixed time. No experiments were performed with initial conditions that would lead to a liquid line of descent along the $\mathrm{KNO}_{3}-\mathrm{NaNO}_{3}$ cotectic curve. Our experiments show good agreement with the corrections to the $\mathrm{KNO}_{3}-\mathrm{H}_{2} \mathrm{O}$ cotectic curve reported by AHW. 

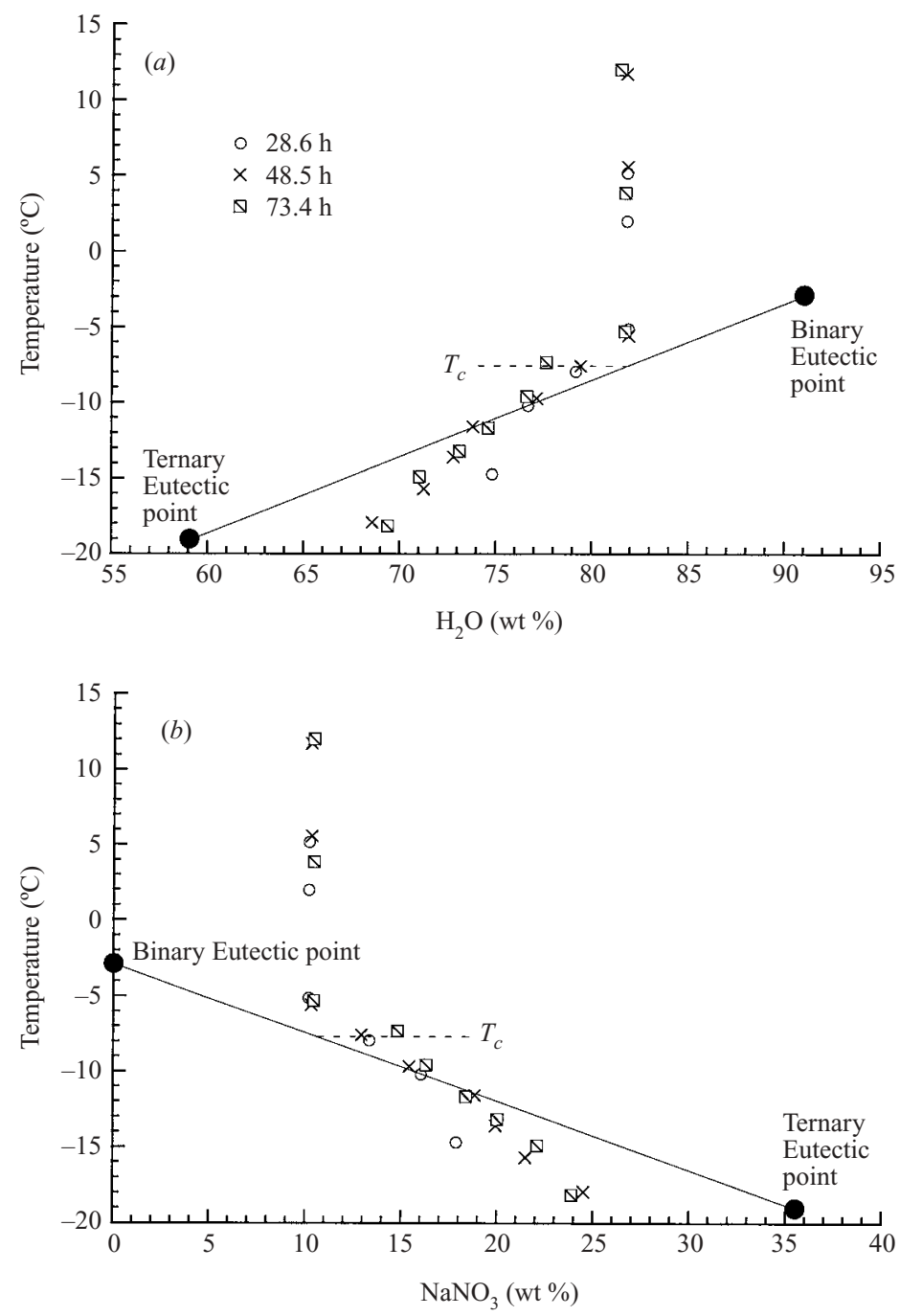

FiguRE 8. The concentrations of $(a) \mathrm{H}_{2} \mathrm{O}$ and $(b) \mathrm{NaNO}_{3}$ in the liquid in experiment 5 as functions of temperature at various times after convection ended. The solid line indicates the linear contectic curve, while the dashed line is at the cotectic temperature $T_{c}$. Data below the dashed line represent samples taken from below the melt-mush interface.

\section{Global conservation model: convective regime}

We now develop a model for the solidification of a ternary alloy cooled from below in a regime where compositional convection influences the growth rates of two separate mushy layers during a transient period. For simplicity of notation, we label the components of the system A, B and C in order of increasing density, and we will use $\mathscr{A}, \mathscr{B}$ and $\mathscr{C}$ to represent concentrations. With respect to our experiments, A, B and $\mathrm{C}$ refer to $\mathrm{H}_{2} \mathrm{O}, \mathrm{KNO}_{3}$ and $\mathrm{NaNO}_{3}$ respectively. We consider a liquid line of descent that falls in field $\mathrm{B}$ and eventually descends along the $\mathrm{AB}$ cotectic curve. We adopt the one-dimensional model represented in figure 10. Preferential incorporation of B into solid in the primary mush leads to depletion of this solute in the rejected 

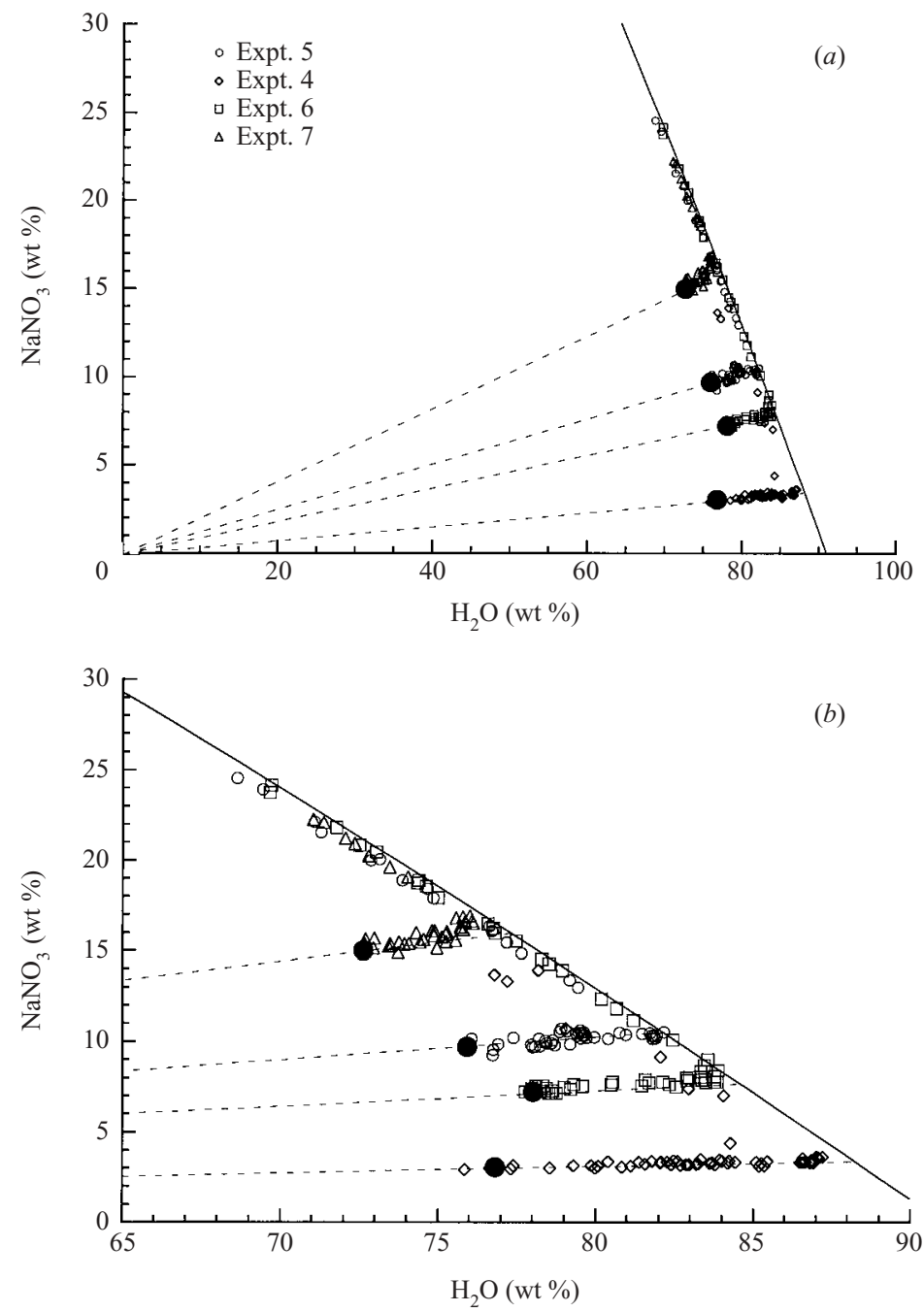

FIGURE 9. Concentration data from experiments 4, 5, 6 and 7 plotted on the phase diagram. (a) The dashed lines from the origin through the large solid circles are the tie lines along the liquidus surface. The solid circles are the initial concentrations. The solid curve is the $\mathrm{KNO}_{3}-\mathrm{H}_{2} \mathrm{O}$ cotectic curve as reported by AHW. (b) Detail of the phase diagram shown in $(a)$.

fluid, making it less dense than the melt above. The cotectic layer is composed of solids A and B and residual liquid. For this specific alloy, a sufficient amount of A solidifies such that the rejected fluid is denser than the residual liquid in the primary mush layer above. At temperatures below the eutectic temperature, all the remaining liquid solidifies into a composite solid. In the current analysis, we will limit our study to sub-cotectic but super-eutectic base temperatures.

The alloy, bounded from below by a horizontal planar boundary and having a depth $H$, is initially in the liquid phase at a temperature $T_{0}$. At time $t=0$, the temperature at the base drops to $T_{b}$ which is below the cotectic temperature $T_{c}$, but greater than the eutectic temperature $T_{e}$. This specification of base temperature agrees with the range 


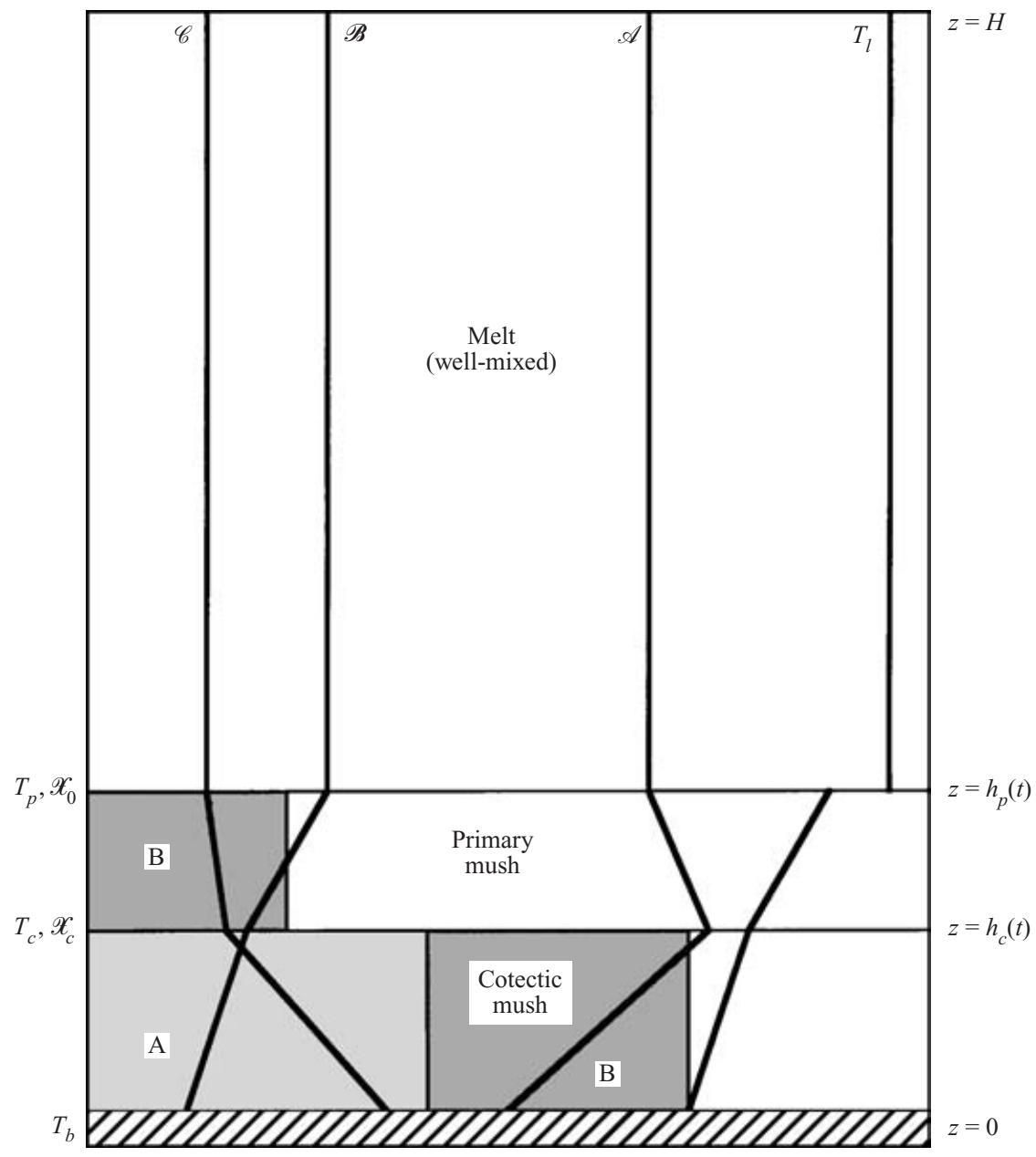

FIGURE 10. Schematic diagram of a ternary alloy cooled from below in a regime where compositional convection occurs only in the primary mush layer. The base temperature $T_{b}$ is less than the cotectic temperature but greater than the eutectic temperature. This leads to the formation of a primary mush and a cotectic mush which grow into the melt. These layers are separated by two distinct planar interfaces at $h_{p}(t)$ and $h_{c}(t)$. The assumption that convection keeps the melt well-mixed is incorporated here by the temperature and concentration values in the melt being independent of height. The approximation of constant solid fractions $\phi$ within a layer is shown and the temperature profiles are linear under the assumption that $\mathrm{d} \phi / \mathrm{d} t$ is small after early times. Local thermodynamic equilibrium couples the concentrations in the residual liquid, $\mathscr{X}=\mathscr{A}, \mathscr{B}, \mathscr{C}$, to the temperature so that the concentration also varies linearly with height in the mushy layers.

of constant baseplate temperatures we were able to maintain in our experiments, and also eliminates the need to consider zonation of the eutectic solid (cf. Kerr et al. $1990 b$ ). Under these conditions, three distinct layers form, namely melt, primary mush and cotectic mush, which are separated by two horizontal planar interfaces, $z=h_{p}(t)$ and $z=h_{c}(t)$. The primary mush is composed of solid B and residual liquid with a solid fraction $\phi_{p}^{B}<1$, and the cotectic mush is composed of solid A, solid B and residual liquid with the solid fractions $\phi_{c}^{A}+\phi_{c}^{B}<1$. 
The global conservation model described here is based on the model introduced by Huppert \& Worster (1985) for a binary alloy. Our model is also similar to the global conservation model for diffusion-controlled growth of a ternary alloy described by Thompson, Huppert \& Worster (2003) with the important addition that the current model allows for convection and time-dependent solid fractions. The model begins with exact equations for the conservation of heat and solute in each layer, and then applies a simplifying assumption about the shape of the solid fraction in these layers. In the model we allow the solid fractions to represent depth-averaged values at every time step, and therefore they are independent of height.

The model also assumes that local thermodynamic equilibrium holds throughout the mushy layers and that temperature and solute concentrations conform to the liquidus relationships. We further assume that a displaced parcel of fluid conforms to the liquidus relationships on time scales that are much shorter than the solutal diffusive time scale. Therefore equilibrium processes dominate in the mushy layer and the effects of solutal diffusivity can be neglected in this region. We assume that the difference in concentration across the primary mush drives convection and that convection keeps the melt well-mixed at all times. The experiments support this assumption as the transition from a convective to a diffusion-limited state was rapid. For simplicity we only consider the effect of the concentration gradient of component B on the stability of the system. Although depletion of component B and enrichment of component $\mathrm{C}$ in the primary mush have opposite effects on the stability of the residual liquid, the concentration gradient of $\mathrm{C}$ is small compared to that of $\mathrm{B}$ for the $\mathrm{H}_{2} \mathrm{O}-\mathrm{KNO}_{3}-\mathrm{NaNO}_{3}$ alloy. As the difference in concentration between the melt and primary mush becomes small the stabilizing effect of the temperature field will become important, and may explain why we observed convection stopping slightly before the melt reached cotectic concentrations in some of our experiments.

Another common assumption is to approximate the liquidus surfaces by planar surfaces and the cotectic curves by straight lines, so that the liquid line of descent follows a piecewise linear curve. Then, given information about the phase diagram, these assumptions allow the liquidus and cotectic points to be determined from the initial conditions of the system. Typically, the planar liquidus surfaces are defined by the freezing point of the component that first solidifies, the binary eutectic point between the two solid components found in the cotectic mush, and the ternary eutectic point. In our experiments, though, the evolution of the residual liquid followed a liquid line of descent in a region localized around the cotectic curve. Rather than applying the freezing point of component $\mathrm{B}$, which would introduce needless error, we use a point on the AB binary liquidus curve that is specified by the saturation data for components $\mathrm{A}$ and $\mathrm{B}$. The three points of interest are then the saturation point $\left(\mathscr{A}_{\text {sat }}\right.$, $\left.\mathscr{C}=0, T_{\text {sat }}\right)$, the binary eutectic point of A and $\mathrm{B}\left(\mathscr{A}_{b e}, \mathscr{C}=0, T_{b e}\right)$, and the ternary eutectic point $\left(\mathscr{A}_{e}, \mathscr{C}_{e}, T_{e}\right)$. We choose to use the concentrations of component $\mathrm{A}$ and $\mathrm{C}$ in determining the liquidus relationships since the tie line passes through the corner of pure $\mathrm{B}$ on the phase diagram, or $0 \mathrm{wt} \% \mathrm{~A}$ and $\mathrm{C}$, which we take as our origin (cf. figure 9). Then the liquidus temperature $T_{p}$ and the cotectic temperature $T_{c}$ are given by

$$
\begin{gathered}
T_{p}=T_{\text {sat }}-m\left(\mathscr{A}_{0}-\mathscr{A}_{\text {sat }}\right)-n \mathscr{C}_{0}, \\
T_{c}=\frac{T_{e}+m_{c}\left[\left(T_{\text {sat }}+m \mathscr{A}_{\text {sat }}\right) / m_{p}-\mathscr{A}_{e}\right]}{1+m_{c} / m_{p}}
\end{gathered}
$$


where $\mathscr{A}_{0}$ and $\mathscr{C}_{0}$ are the initial concentrations and $m, n, m_{p}$ and $m_{c}$ are the following slopes on the phase diagram:

$$
\begin{gathered}
m=\frac{T_{s a t}-T_{b e}}{\mathscr{A}_{b e}-\mathscr{A}_{s a t}}, \\
n=\frac{T_{s a t}-T_{e}-m\left(\mathscr{A}_{e}-\mathscr{A}_{s a t}\right)}{\mathscr{C}_{e}}, \\
m_{p}=m+\frac{\mathscr{C}_{0}}{\mathscr{A}_{0}} n \\
m_{c}=\frac{T_{b e}-T_{e}}{\mathscr{A}_{b e}-\mathscr{A}_{e}} .
\end{gathered}
$$

The concentrations at the cotectic point $\mathscr{A}_{c}$ and $\mathscr{C}_{c}$ can be found using equation (3.1) by replacing $T_{p}$ with $T_{c}$ and using the fact that $\mathscr{A}_{c}=\left(\mathscr{A}_{0} / \mathscr{C}_{0}\right) \mathscr{C}_{c}$ at the cotectic point.

\subsection{Model with empirical fluxes}

Each of the three layers in this model is considered as a continuum with a separate set of equations governing the dynamics in that region. Boundary conditions are provided at the interfaces between the different layers using the liquidus relationships, and the growth rates are coupled by conservation of heat at the interfaces. Unlike the diffusion-limited case, solute can be transported vertically due to convection, which modifies our equations for solute conservation. In the following analysis, subscripts $l$, $p$ and $c$ stand for the melt, primary mush and cotectic mush respectively.

In the melt, $H>z>h_{p}(t)$, convection keeps the liquid well-mixed so that

$$
\begin{aligned}
T=T_{l}(t) \\
\mathscr{X}=\mathscr{X}_{l}(t), \quad \mathscr{X}=\mathscr{B}, \mathscr{C},
\end{aligned}
$$

and we assume that these concentrations are equal to their values at the melt-mush interface. The convective heat flux $F_{T}$ and the solute flux $F_{C}$ between the melt and the mush can then be determined from the evolution of temperature and concentration in the melt. We include a discussion of the relationship between $F_{T}$ and $F_{C}$ below, but in our simulations we applied empirical data from the melt and calculated the fluxes from the relationships

$$
\begin{gathered}
F_{C}=-\left(H-h_{p}\right) \frac{\mathrm{d} \mathscr{B}_{l}}{\mathrm{~d} t}, \\
F_{T}=-\rho C_{p}\left(H-h_{p}\right) \frac{\mathrm{d} T_{l}}{\mathrm{~d} t},
\end{gathered}
$$

where a positive value of $F_{C}$ or $F_{T}$ represents a flux from the melt into the primary mush. Again we note that our assumption of convection being driven solely by the concentration gradient in component $\mathrm{B}$ might not be valid for all alloys. Rejection of solute $\mathrm{C}$ would tend to reduce the value of both $F_{C}$ and $F_{T}$.

In the global conservation models of diffusion-controlled solidifying alloys, the solid fractions are independent of time. Then applying the quasi-stationary approximation (linear temperature profile), latent heat is only released at the interfaces as the mushy layers grow vertically. If the depth-averaged solid fractions are dependent on time, though, there can also be a release of latent heat within the mushy layer due to changes in the solid fraction. Kerr et al. (1990a) show that when the global conservation model is applied to a solidification problem where the solid fractions $\phi$ are assumed uniform but vary with time, the temperature profile is quadratic. This 
temperature profile modifies the Stefan condition by introducing a new term that accounts for the latent heat release within the mush. The Stefan condition at the melt-mush interface, $z=h_{p}(t)$, becomes

$$
\left[\rho C_{p}\left(T_{l}-T_{p}\right)+\phi_{p}^{B} \rho_{B} L_{B}\right] \frac{\mathrm{d} h_{p}}{\mathrm{~d} t}+\frac{1}{2} \rho_{B} L_{B}\left(h_{p}-h_{c}\right) \frac{\mathrm{d} \phi_{p}^{B}}{\mathrm{~d} t}=\overline{k_{p}} \frac{\left(T_{p}-T_{c}\right)}{\left(h_{p}-h_{c}\right)}-F_{T},
$$

where $\rho$ and $C_{p}$ are the density and specific heat of the melt, $\rho_{B}$ and $L_{B}$ are the density and the latent heat release of solid $\mathrm{B}$ and $\overline{k_{p}}$ is the average thermal conductivity of the primary mush, given by

$$
\overline{k_{p}}=\phi_{p}^{B} k_{B}+\left(1-\phi_{p}^{B}\right) k_{l}
$$

as discussed by Batchelor (1974). We will assume that the effect of the quadratic term is small since $\mathrm{d} \phi / \mathrm{d} t$ is only significant when the height of the mushy layers are very small. Therefore we can continue to use the approximation that temperature varies linearly with height in the mushy layers.

Conservation of solute $\mathrm{B}$ in the primary mush is expressed by

$$
\int_{h_{c}}^{h_{p}}\left[\left(1-\phi_{p}^{B}\right) \mathscr{B}+\phi_{p}^{B} \frac{\rho_{B}}{\rho_{l}} \mathscr{B}_{s}\right] \mathrm{d} z=\overline{\mathscr{B}}_{p}(t)\left(h_{p}(t)-h_{c}(t)\right),
$$

in which we include the effects of a change in density between the liquid and solid phase but assume that the depth of the alloy $H$ remains constant since $H \gg$ $h_{p}$. Here $\mathscr{B}_{s}$ represents the concentration of solid B and is equal to $100 \mathrm{wt} \%$ if solid immiscibility is assumed, and $\overline{\mathscr{B}}_{p}$ represents the bulk concentration of solute $\mathrm{B}$ in the primary mush. In the diffusion-limited regime the bulk concentration is constant, but here it changes with time due to vertical solute transport. At this point we apply our approximations that the solid fraction is independent of height and, as discussed above, that the temperature profile is approximately linear. Local thermodynamic equilibrium and a piecewise linear liquid line of descent then prescribe that concentration must also vary linearly with height in the mushy layers, and we can modify (3.13) to obtain

$$
\overline{\mathscr{B}}_{p}=\frac{1}{2}\left(1-\phi_{p}^{B}\right)\left(\mathscr{B}_{l}+\mathscr{B}_{c}\right)+\phi_{p}^{B}\left(\rho_{B} / \rho_{l}\right) \mathscr{B}_{s},
$$

where $\mathscr{B}_{l}$ and $\mathscr{B}_{c}$ are the concentrations at the upper and lower interfaces of the primary mush. The bulk concentration of solute B in the primary mush changes due to the growth of this layer into the melt and a deposition of salt caused by the solute flux. The growth of the cotectic mush into the primary mush does not alter the bulk concentration in the primary mush. This relationship can be written as

$$
\left(h_{p}-h_{c}\right) \frac{\mathrm{d} \overline{\mathscr{B}}_{p}}{\mathrm{~d} t}=\left(\mathscr{B}_{l}-\overline{\mathscr{B}}_{p}\right) \frac{\mathrm{d} h_{p}}{\mathrm{~d} t}+F_{C} .
$$

At the interface between the primary and cotectic mushes, $z=h_{c}(t)$, the Stefan condition becomes

$$
\begin{aligned}
{\left[\phi_{c}^{A} \rho_{A} L_{A}+\left(\phi_{c}^{B}-\phi_{p}^{B}\right) \rho_{B} L_{B}\right] \frac{\mathrm{d} h_{c}}{\mathrm{~d} t}+\frac{1}{2} h_{c}\left(\rho_{A} L_{A} \frac{\mathrm{d} \phi_{c}^{A}}{\mathrm{~d} t}+\rho_{B} L_{B} \frac{\mathrm{d} \phi_{c}^{B}}{\mathrm{~d} t}\right) } \\
=\overline{k_{c}} \frac{\left(T_{c}-T_{b}\right)}{h_{c}}-\overline{k_{p}} \frac{\left(T_{p}-T_{c}\right)}{\left(h_{p}-h_{c}\right)},
\end{aligned}
$$

where the averaged thermal conductivity in the cotectic mush is

$$
\overline{k_{c}}=\phi_{c}^{A} k_{A}+\phi_{c}^{B} k_{B}+\left(1-\phi_{c}^{A}-\phi_{c}^{B}\right) k_{l} \text {. }
$$


In the cotectic mush, we must define conservation equations for both solutes so that

$$
\begin{gathered}
\int_{0}^{h_{c}}\left[\left(1-\phi_{c}^{A}-\phi_{c}^{B}\right) \mathscr{B}+\phi_{c}^{B}\left(\rho_{B} / \rho_{l}\right) \mathscr{B}_{s}\right] \mathrm{d} z=\overline{\mathscr{B}}_{c}(t) h_{c}(t), \\
\int_{0}^{h_{c}}\left(1-\phi_{c}^{A}-\phi_{c}^{B}\right) \mathscr{C} \mathrm{d} z=\overline{\mathscr{C}}_{c}(t) h_{c}(t),
\end{gathered}
$$

where $\overline{\mathscr{B}}_{c}$ and $\overline{\mathscr{C}}_{c}$ are the bulk concentrations of the two solutes in the cotectic mush. These equations can be simplified to

$$
\begin{gathered}
\overline{\mathscr{B}}_{c}=\frac{1}{2}\left(1-\phi_{c}^{A}-\phi_{c}^{B}\right)\left(\mathscr{B}_{c}+\mathscr{B}_{b}\right)+\phi_{c}^{B}\left(\rho_{B} / \rho_{l}\right) \mathscr{B}_{s}, \\
\overline{\mathscr{C}}_{c}=\frac{1}{2}\left(1-\phi_{c}^{A}-\phi_{c}^{B}\right)\left(\mathscr{C}_{c}+\mathscr{C}_{b}\right)
\end{gathered}
$$

by assuming a linear temperature profile, local thermodynamic equilibrium and solid fractions independent of depth. In these equations $\mathscr{B}_{b}$ and $\mathscr{C}_{b}$ are the concentrations at the base of the alloy $(z=0)$. The change in bulk concentration within the cotectic layer is only influenced by the growth of the cotectic layer into the primary mush so that

$$
\begin{aligned}
h_{c} \frac{\mathrm{d} \overline{\mathscr{B}}_{c}}{\mathrm{~d} t} & =\left(\overline{\mathscr{B}}_{p}-\overline{\mathscr{B}}_{c}\right) \frac{\mathrm{d} h_{c}}{\mathrm{~d} t}, \\
h_{c} \frac{\mathrm{d} \overline{\mathscr{C}}_{c}}{\mathrm{~d} t} & =\left(\overline{\mathscr{C}}_{p}-\overline{\mathscr{C}}_{c}\right) \frac{\mathrm{d} h_{c}}{\mathrm{~d} t} .
\end{aligned}
$$

With empirical data provided for $T_{l}(t)$ and $\mathscr{B}_{l}(t)$, values for $h_{p}, h_{c}, \overline{\mathscr{B}}_{p}, \overline{\mathscr{B}}_{c}$ and $\overline{\mathscr{C}}_{c}$ can all be determined in an iterative time-stepping procedure. The depth-averaged solid fractions can then be computed from the bulk concentration of solute in each layer. The current model concentrates on the solidification process until convection ceases in the alloy. Once $\Delta \mathscr{B}=0$ the growth of the alloy is once again diffusionlimited. At this time only one (cotectic) mushy layer remains, which contains both solids A and B and residual liquid. The heat flux term in the Stefan condition (3.11) becomes zero, but the solid fraction would continue to vary with time in the global conservation model until the bulk concentration is uniform throughout the alloy.

\subsection{Flux relationships}

As can be seen from (3.11), the conduction of heat through the mush must always balance the latent heat released during the formation of solid and the convective heat flux. At very early times the growth rates of the mushy layers are large, so we expect conduction to balance the large latent heat release. When this occurs, the growth rates of the mushy layers are diffusion-limited. As convection becomes stronger, warm liquid from the melt is brought into contact with the mush and limits the growth rate of this layer. In the experiments described above, the convective heat flux varies with time and eventually vanishes. Once the fluid in the primary mush is no longer buoyant, the growth rates of the mushy layers are again diffusion-limited and the balance between conduction and latent heat is recovered. Turner, Huppert \& Sparks (1986) first modelled a system of this form, and the different balances were later described in detail by Huppert \& Worster (1991).

From this analysis it is clear that accurately modelling the relationship between the solute flux away from the interface and the heat flux towards the interface is essential to understanding the dynamics of the system. Studies attempting to parameterize this 
relationship have been carried out by Woods \& Huppert (1989) for compositional convection at the interface between a solid and melt and by Worster (1990) for a mushy layer where compositional convection was primarily through chimneys. Both of these studies suggested a relationship in which the solute flux $F_{C}$ is proportional to some power of the concentration gradient (in our experiments $\Delta \mathscr{B}$ ) that is driving convection,

$$
\frac{\mathrm{d} \Delta \mathscr{B}}{\mathrm{d} t} \sim-F_{C} \propto-(\Delta \mathscr{B})^{\eta}
$$

From our experimental observations we expect that $\Delta \mathscr{B}=0$ after a finite time, and therefore $\eta<1$.

We consider a simple scaling argument where the convective heat flux is balanced by conduction through a single mushy layer and is related to $F_{C}$ by

$$
F_{T} \sim k \frac{\Delta T}{h} \sim \frac{\Delta T}{\Delta \mathscr{B}} F_{C}
$$

where $k$ is the thermal conductivity of the melt, $h$ is the height of the mushy layer and $\Delta T$ is the temperature difference between the melt and the melt-mush interface. If the height of the mush is small compared to the height of the tank, we assume that the mushy-layer Raleigh number $R_{m}$ (Worster 2000) is approximately at some constant critical value,

$$
\frac{g \beta \Delta \mathscr{B} \Pi(\phi) h}{\kappa \mathcal{V}} \sim R_{m_{\text {crit }}},
$$

where $\kappa$ is the thermal diffusivity, $v$ is the dynamic viscosity, $g$ is accelaration due to gravity, $\beta$ is a compositional expansion coefficient and $\Pi$ is the permeability of the mush, which is a function of the solid fraction. It can then be shown by rearranging (3.25) and (3.26) that

$$
F_{C} \sim(\Delta \mathscr{B})^{2} \Pi(\phi) .
$$

Chen \& Chen (1991) and Tait \& Jaupart (1992) have applied the full Kozeny-Carman law (Phillips 1991) to (3.27) where $\Pi$ is principally dependent on $\phi$. Fowler (1985) and Worster (1992) have suggested that a possible relationship between the permeability and concentration difference is $\Pi \propto 1 /(\Delta \mathscr{B})^{3}$, which would allow the solute flux to become zero in a finite time. In $\S 5.3$ we compare this result with our model using empirical data for the concentration evolution within the melt. These relationships still remain somewhat uncertain, though, and future experiments will be needed to investigate this problem thoroughly.

\section{Results: $F_{T} \equiv 0$}

We will first consider a simplified version of the model described in the previous section by analysing the solidification of our experimental alloy in a semi-infinite tank in the absence of gravity. Without the effects of convection, the system becomes diffusion-limited (Huppert \& Worster 1985). Since there is no longer any mechanism for the vertical transport of solute, the bulk concentration is uniform throughout the alloy and independent of time. Application of the shape assumption for the solid fractions in the global conservation model implies that the solid fraction values are constant. Anderson (2003) has derived a full local conservation model for diffusioncontrolled solidification of a ternary alloy, and in an appendix to that work, Thompson et al. (2003) described the global conservation model for this regime. For both models similarity solutions were found for the interface positions of the mushy layers and 


\begin{tabular}{lccc} 
& $T_{b}\left[{ }^{\circ} \mathrm{C}\right]$ & $\mathscr{A}_{0}[\mathrm{wt} \%]$ & $\mathscr{C}_{0}[\mathrm{wt} \%]$ \\
Reference values & -15.0 & 75.0 & 7.0 \\
Range of variation & $-19.0-8.45$ & $70.0-84.7$ & $2.0-17.0$ \\
\multicolumn{4}{r}{ Material information for the reference values } \\
Liquidus point & 8.45 & 75.0 & 7.0 \\
Cotectic point & -6.41 & 84.0 & 7.84 \\
Base & -15.0 & 67.0 & 26.7
\end{tabular}

TABLE 3. List of reference values and their material parameters for the $\mathrm{H}_{2} \mathrm{O}-\mathrm{KNO}_{3}-\mathrm{NaNO}_{3}$ alloy analysed in $\S 4 . \mathscr{A}_{0}$ and $\mathscr{C}_{0}$ represent the initial concentrations of $\mathrm{H}_{2} \mathrm{O}$ and $\mathrm{KNO}_{3}$ respectively. The range of variations are the values over which each parameter was varied individually. The material information for the liquidus point, cotectic point and the base are determined from the ternary phase diagram using the approximation of a piecewise linear tie line.

the eutectic solid. The global conservation model of Thompson et al. (2003) is used in this section to analyse the effect of the experimental parameters on the solid fraction values.

In Anderson (2003) and Thompson et al. (2003), results from both the local and global conservation models showed how changes in the initial conditions of the system (baseplate temperature, initial alloy temperature and initial concentrations) affected the growth rates of the two mushy layers and the eutectic solid. Variations in the baseplate temperature and in the initial concentrations also affect the solid fraction values. We note that the solid fractions are again depth-averaged values in this model, and discontinuities in the solid fraction of a given component at an interface are allowed.

We begin by considering the $\mathrm{A}-\mathrm{B}-\mathrm{C} \equiv \mathrm{H}_{2} \mathrm{O}-\mathrm{KNO}_{3}-\mathrm{NaNO}_{3}$ alloy described in our experiments. A full list of the material parameters of this alloy appears in Thompson et al. (2003). We also choose a set of reference initial conditions from which the baseplate temperature and initial concentrations will be varied individually. These reference values and the ranges over which each parameter is varied are listed in table 3 along with the corresponding liquidus and cotectic points assuming a planar liquidus surface and linear cotectic curve.

Figure 11 shows the change in solid fractions in the primary and cotectic mushes caused by variations in the baseplate temperature. Specification of the baseplate temperature in turn specifies the concentration of the residual liquid at $z=0$ since the two values are coupled by local thermodynamic equilibrium. This change in concentration at the base of the mushes then affects the solid fraction values. We vary the baseplate temperature from the liquidus temperature to the ternary eutectic temperature. The liquidus temperature $T_{p}$ represents the point at which solidification is just beginning to occur, and therefore the solid fraction of the primary mush approaches zero as the base temperature approaches $T_{p}$ from below. The solid fraction within the primary mush increases linearly as the temperature is lowered to the cotectic temperature because of our assumption of a linear liquidus curve. At the cotectic temperature $T_{c}$ solid fractions for both components A and B form. Since only solid B is present in the primary mush, $\phi_{c}^{A}$ approaches zero at the cotectic temperature in the same way that $\phi_{p}^{B}$ approaches zero at the liquidus temperature. 


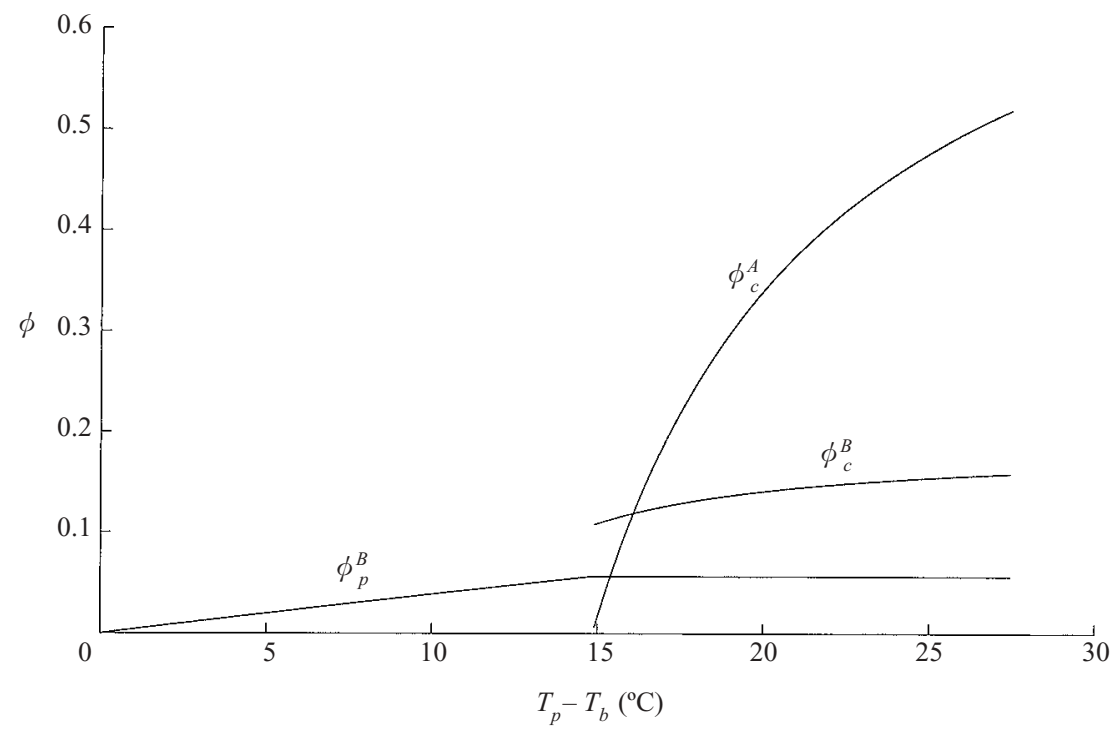

FIGURE 11. Variation in the solid fractions with changes in the base temperature $T_{b}$ as determined by the global conservation model for a non-convecting ternary alloy. For the alloy used in this simulation, $T_{p}=8.45^{\circ} \mathrm{C}$ and $T_{c}=-6.41{ }^{\circ} \mathrm{C}$. The values of the parameters kept constant in this simulation are listed in table 3.

A discontinuity between $\phi_{p}^{B}$ and $\phi_{c}^{B}$ exists at the primary-cotectic mush interface because of our adoption of depth-averaged solid fraction values.

The value of $\phi_{p}^{B}$ is dependent only on the concentrations at the upper and lower boundaries of the primary mush. Therefore it remains constant once the baseplate temperature drops below the cotectic temperature. The change in solid fractions is no longer linear in the cotectic mush because the solid fractions depend on the concentrations of both solutes. Although not depicted in figure 11, at temperatures below eutectic and in the absence of vertical solute transport, conservation of mass requires that the solid fractions in the composite eutectic solid are proportional to the ratios of the initial concentrations.

Figure $12(a)$ shows the variation in solid fraction with a change in $\mathscr{C}_{0}$. As the initial concentration of component $\mathrm{C}$ increases, the distance between the liquidus point and the cotectic point becomes smaller. This corresponds to a smaller concentration change over the primary mush and a decrease in the magnitude of $\phi_{p}^{B}$. As the initial concentration of $\mathscr{C}_{0}$ approaches the cotectic curve, the solid fraction in the primary mush approaches zero. This occurs because, in the special case where initial concentrations fall on a cotectic curve, a single mushy layer forms consisting of two solid components and a residual liquid. Increasing the concentration of $\mathscr{C}_{0}$ causes the cotectic point to move along the cotectic curve towards the concentrations imposed by the base temperature (cf. figure 9). This reduces the concentration gradient across the cotectic mush, and leads to a decrease in the values of $\phi_{c}^{A}$ and $\phi_{c}^{B}$. Also, in general, increasing the value of $\mathscr{C}_{0}$ implies that there are smaller amounts of components A and $\mathrm{B}$ in the alloy because the sum of $\mathscr{A}_{0}, \mathscr{B}_{0}$ and $\mathscr{C}_{0}$ must be $100 \mathrm{wt} \%$. This also contributes to the decrease in solid fractions since only solid A and B form in the mushy layers. 

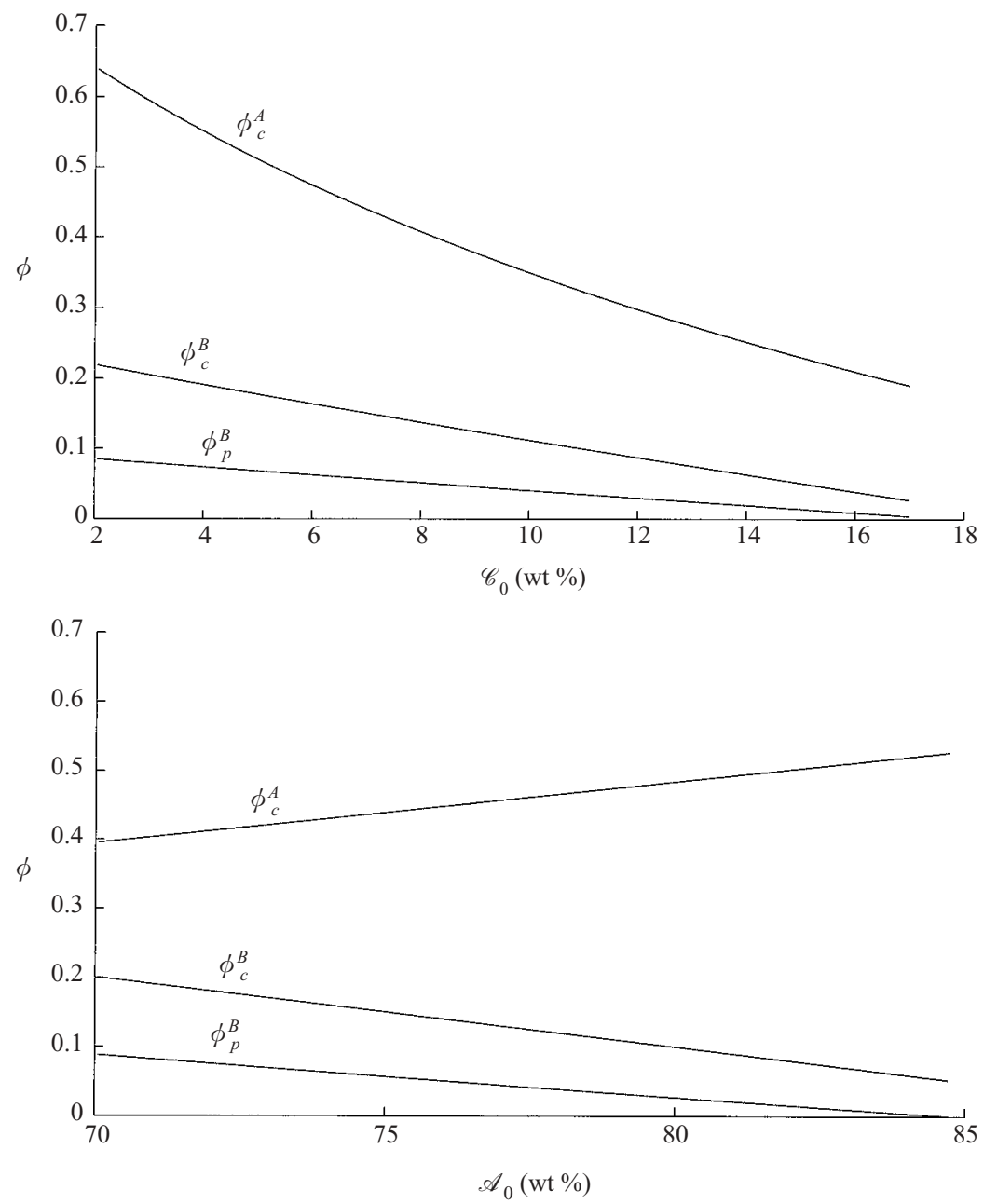

FIGURE 12. Variations in the solid fractions with changes $(a)$ in the initial concentration of $\mathrm{C}$ and $(b)$ in the initial concentration of $\mathrm{A}$ as determined by the global conservation model for a non-convecting ternary alloy. The values of the parameters kept constant in this simulation are listed in table 3.

A similar analysis can be performed when the initial concentration of component A is varied, as shown in figure $12(b)$. Changes in the initial concentration of component A have a smaller effect on the solid fractions because of the region of the phase diagram in which the experiments were conducted. Large changes in the initial concentration of A only have a small effect on the location of the cotectic point on the phase diagram. Still, some interesting features can be observed. First, just as approaching the cotectic curve by varying $\mathscr{C}_{0}$ caused $\phi_{p}^{B}$ to approach zero, so the liquidus point approaches the cotectic curve due to changes in $\mathscr{A}_{0}$. Increasing the initial concentration of component A causes the cotectic point to move slightly further from the base concentrations on the cotectic curve, which corresponds to an increase in $\phi_{c}^{A}$. Since the cotectic concentrations of components A and C (and therefore B) remain nearly constant for the tie lines over the range of $\mathscr{A}_{0}$, the observed decrease in 
$\phi_{c}^{B}$ with increasing $\mathscr{A}_{0}$ is primarily caused by a reduction in the bulk concentration of solute B.

In the convecting case, the evolution of the melt follows a tie line, which is very similar to varying $\mathscr{A}_{0}$ as described above (changes in $\mathscr{C}$ are small). In the cases discussed here, however, each different solid fraction value represents a different realization of the simulation where the initial concentration, or solute content, of the alloy was changed. With convection, the change in concentration at the upper boundary of the mushy layer will still influence the solid fractions by increasing or reducing the concentration gradient over a layer, but now a more important effect is that changes in concentration in the melt must be balanced by changes in the solid fractions in the mushy layers in order to conserve solute.

\section{Results: full model}

We now consider the full model developed in $\S 3.1$ where the solidification process takes place in a gravitational field, and buoyancy forces give rise to convection that significantly alters the behaviour of the system. In this model, convection only occurs within the primary mush and the melt layers due to a compositional instability (the thermal field is stably stratified at all times). In reality this convection may cause fluid motion in the cotectic layer as well, but thermistor traces suggest that this flow is very weak. Convection also stops completely after a finite period of time. When convection has ceased the melt-mush interface has concentrations equivalent to the alloy's cotectic concentrations and therefore only a single mush exists composed of two solids and a residual liquid. The analysis in this section concentrates primarily on the convective regime until the transition to a diffusion-controlled system occurs.

This model provides information about the interface positions $h_{p}(t)$ and $h_{c}(t)$ and the depth-averaged solid-fraction values $\phi_{p}^{B}(t), \phi_{c}^{A}(t)$ and $\phi_{c}^{B}(t)$. The assumptions discussed in $\S 3.1$ still apply. The model uses empirical data for the evolution of temperature and concentration in the melt, which provides empirical values for the solute flux and convective heat flux through (3.9) and (3.10).

We initialize the model with small height values for the primary and cotectic mush to avoid the singularity in the Stefan conditions at time $t=0$. The heights are initialized based on the asymptotic limit of a similarity solution for growth in a diffusion-controlled regime. We make this assumption because at early times the growth rate is large and the principal balance is between conduction and latent heat release (Huppert \& Worster 1991). Temperature and concentration values are also initialized at the two interfaces and at $z=0$ based on the initial conditions $\mathscr{B}_{0}, \mathscr{C}_{0}, T_{0}$ and $T_{b}$ and the corresponding liquid line of descent. We consider cases where $T_{c}>T_{b}>T_{e}$ and $T_{b}$ is a constant. This model can also be easily modified to include empirical values for $T_{b}$ in experiments where the baseplate temperature was not held constant. At the first time step, the concentration of component $B$ $\left(\mathrm{KNO}_{3}\right)$ and temperature in the melt are updated which determines the solute and convective heat fluxes respectively. The heights of the two mushy layers are then updated simultaneously using the Stefan condition at each interface, (3.11) and (3.16), by applying a second-order Runge-Kutta scheme. The updated heights are used to determine the change in solute bulk concentrations in both mushy layers from equations (3.15), (3.22) and (3.23). Finally, the new depth-averaged values of the three solid fractions are determined using (3.14), (3.20) and (3.21). The model continues these iterations until the height of the cotectic mush is just greater than the primary mush, which indicates that convection has stopped. In this model we assume that the 


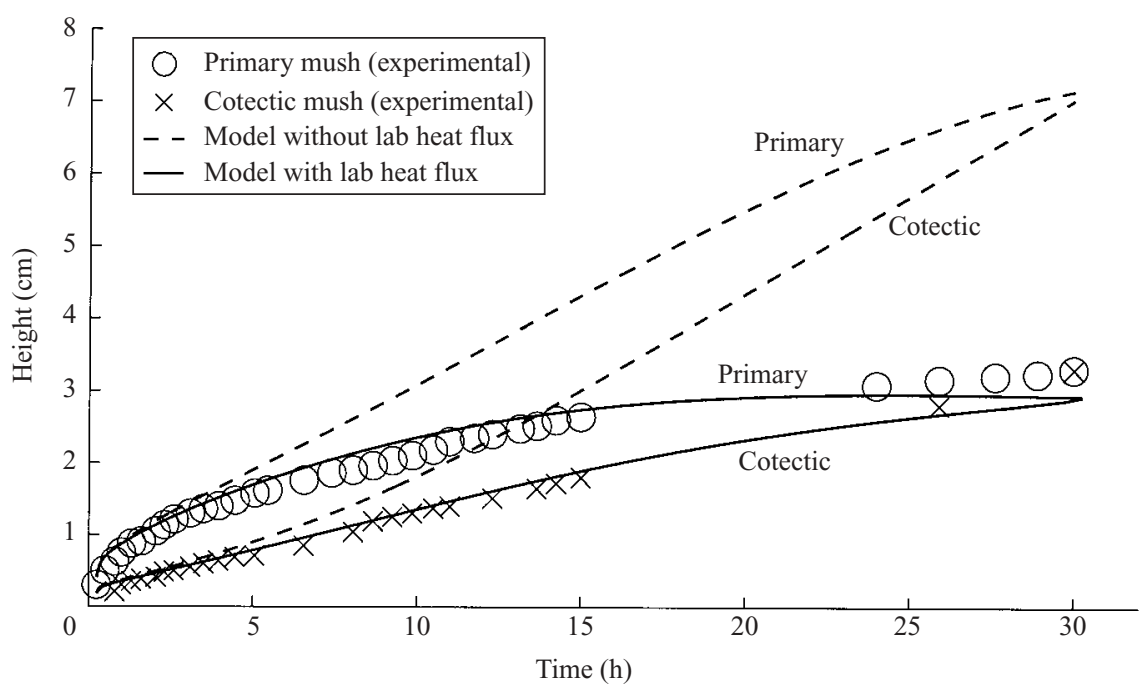

FIGURE 13. Experimental and numerical data for the interface positions of the primary and cotectic mushes from experiment 7. The symbols represent empirical data taken from our experiment. The dashed curves represent a simulation in which the heat flux from the laboratory was not included, while the solid curves represent a simulation where this additional heat flux was included. For this experiment $h^{*}=3.3 \mathrm{~cm}$ and $t^{*}=30 \mathrm{~h}$.

melt remains well-mixed throughout the convective regime. Figure 3 shows that this is a good approximation since, with the exception of fluid near the very top of the tank, the transition from a well-mixed to a stratified melt is relatively abrupt.

\subsection{Interface positions}

In our first simulations, the interface positions of the two mushy layers agreed well with the behaviour we expected to see in a convecting system in which the heat flux term $F_{T}(t)$ is monotonically decreasing. The dashed curves in figure 13 show the interface positions from the simulation using parameters from experiment 7 . At very early times, the growth of the layers was close to the similarity solutions, but the effects of the convective heat flux quickly dominated the latent heat release and limited the heights of the layers compared to diffusion-controlled similarity solution growth. As convection weakened over time, the relationship $h=\lambda t^{1 / 2}$ was recovered, which indicated that the principal heat balance was once again between conduction and latent heat release. The simulation also showed that the cotectic mush eventually overtook the primary mush when the system had become stably stratified compositionally.

The time at which the cotectic mush overtook the primary mush $t^{*}$ showed good agreement with our experiments. This was interesting since in both the observations and the simulations the cotectic mush overtook the primary mush even though the melt had not completely reached cotectic concentrations. On the other hand, the height $h^{*}$ at which this occurred was over a factor of two larger than the experimental observations. In general the simulations seemed to agree well with the experimental data for the first few hours of the solidification process. This suggested that the problem in the model occurred mainly in the conduction-convective heat flux balance, and most likely to be due to an inaccurate modelling of the heat flux term. One possible source of error in this term was the influence of an additional heat 


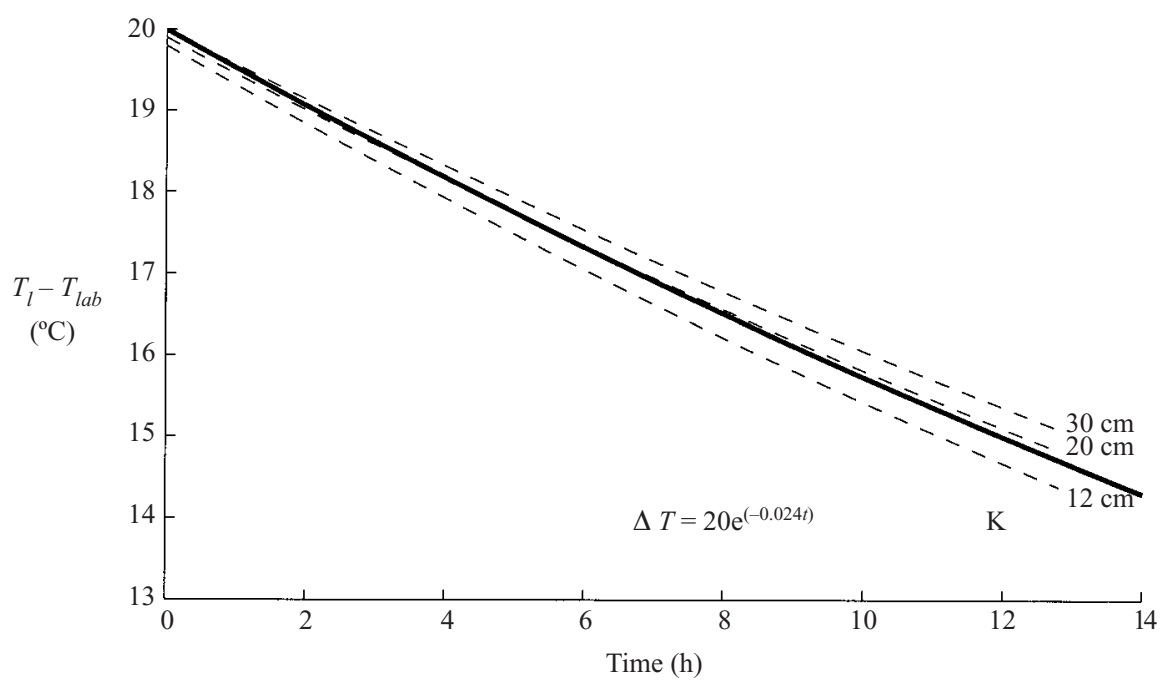

FIGURE 14. Traces from thermistors at 30,20 and $12 \mathrm{~cm}$ above the baseplate as liquid heated to approximately $43.5^{\circ} \mathrm{C}$ is allowed to cool inside the tank used in our experiments at an ambient temperature $T_{l a b}$ of $23.5^{\circ} \mathrm{C}$. The temperature from the thermistors is represented by dashed lines, while an exponential fit with decay constant $\sigma=0.024 \mathrm{~h}^{-1}$ and $\Delta T=T_{l}-T_{\text {lab }}$ is shown with a solid line.

flux between the tank and the laboratory. To measure this quantity we ran a simple experiment in which we filled our experimental tank with water and heated the base, using the same Haake cooling unit, until the fluid was approximately at a uniform temperature of $43.5^{\circ} \mathrm{C}$. At time $t=0$ the heated coolant being pumped through the baseplate was stopped, and the temperature of the fluid as it cooled was recorded by the thermistors. The ambient temperature of the laboratory during this experiment was $23.5^{\circ} \mathrm{C}$.

The traces of thermistors at $30 \mathrm{~cm}, 20 \mathrm{~cm}$ and $12 \mathrm{~cm}$ above the baseplate are shown by the dashed lines in figure 14 for the first thirteen hours of the experiment. The temperature traces were exponential with a decay constant of approximately $\sigma=-0.024 \mathrm{~h}^{-1}$. The heat flux from the laboratory is then given by

$$
F_{T_{l a b}}=-\rho C_{p} H \frac{\mathrm{d} T}{\mathrm{~d} t}=\rho C_{p} H \sigma \Delta T
$$

where $\Delta T=\left(T_{l}-T_{l a b}\right)$. Since we have applied empirical data for the temperature evolution within the melt to determine the convective heat flux, the additional heat flux from the laboratory is simply added to the convective heat flux term and included in $F_{T}$.

The heat flux from the laboratory has a significant effect on the growth dynamics and greatly improved the model's agreement with the experimental observations as shown by the solid curves in figure 13 . The agreement becomes slightly worse towards the end of the convective regime, but this is most likely due to the fact that we have assumed that convection keeps the melt well-mixed until the cotectic mush overtakes the primary mush. Towards the end of the convective regime, however, convection begins to weaken and the heat flux term, which limits growth, would be smaller.

We may expect that a heat flux from the laboratory would have a large effect on the growth rates of the mushy layers for the following reason. The amount of solute 


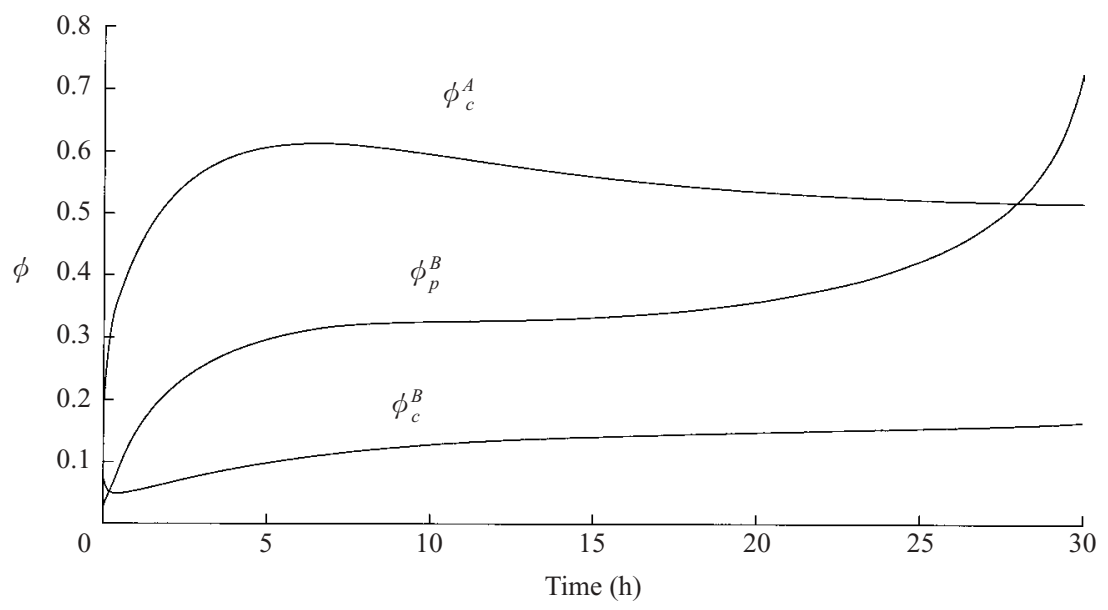

FIGURE 15. Numerical simulation of the evolution of the depth-averaged solid fractions with time using the parameters from experiment 7.

in the primary mush is largely independent of the layer depth because the deposition of salt by the solute flux is the dominant process. If the model's convective heat flux is too small when computing the Stefan condition, the growth of the mush will be too large at each time step, and the resulting solute concentrations will be too small. Then, the amount of latent heat released at the melt-mush interface will also be too small, which will cause the primary mush to grow faster still.

\subsection{Solid fractions}

The simple model developed here also provides some insight into the evolution of the solid fractions over time. In $\S 4$ we analysed how the solid fractions change as they grow into melts with different concentrations. In some respects, the evolution of solid fractions in the convecting case is similar, because the concentration in the melt varies with time. The major difference, though, is that when the concentration in the melt changes, this solute must be conserved in the mushy layers.

Figure 15 shows the solid fractions as a function of time for the simulation shown in figure 13 with the heat flux from the laboratory included. The solid fraction of $\mathrm{KNO}_{3}$ in the primary mush is given by $\phi_{p}^{B}$ while $\phi_{c}^{A}$ and $\phi_{c}^{B}$ represent the solid fractions of $\mathrm{H}_{2} \mathrm{O}$ and $\mathrm{KNO}_{3}$ respectively in the cotectic mush. At early times the solid fraction of $\mathrm{B}$ increases rapidly in the primary mush due to a large positive solute flux. A large increase is also observed in the solid fraction of A. As the solute flux becomes smaller and the primary mush grows into a melt now depleted in solute, the growth of $\phi_{p}^{B}$ slows. The growth of $\phi_{p}^{B}$ continues and eventually increases again as the cotectic mush begins to grow faster than the primary mush and the depth of the primary mush approaches zero. We do not have empirical data for the solid fractions, and this high value could be a consequence of using the global conservation model which we will discuss below. As the cotectic mush grows into a layer where $\phi_{p}^{B}$ is increasing, smaller amounts of components $\mathrm{A}$ and $\mathrm{C}$ are incorporated into the cotectic mush. This is because the concentration in the residual liquid at the primary-cotectic mush interface remains constant, but the liquid fraction decreases. Thus, $\phi_{c}^{A}$ decreases slowly after about five hours. The solid fraction of $\mathrm{B}$ in the cotectic mush increases steadily throughout the simulation except for a very short period at the start of the 

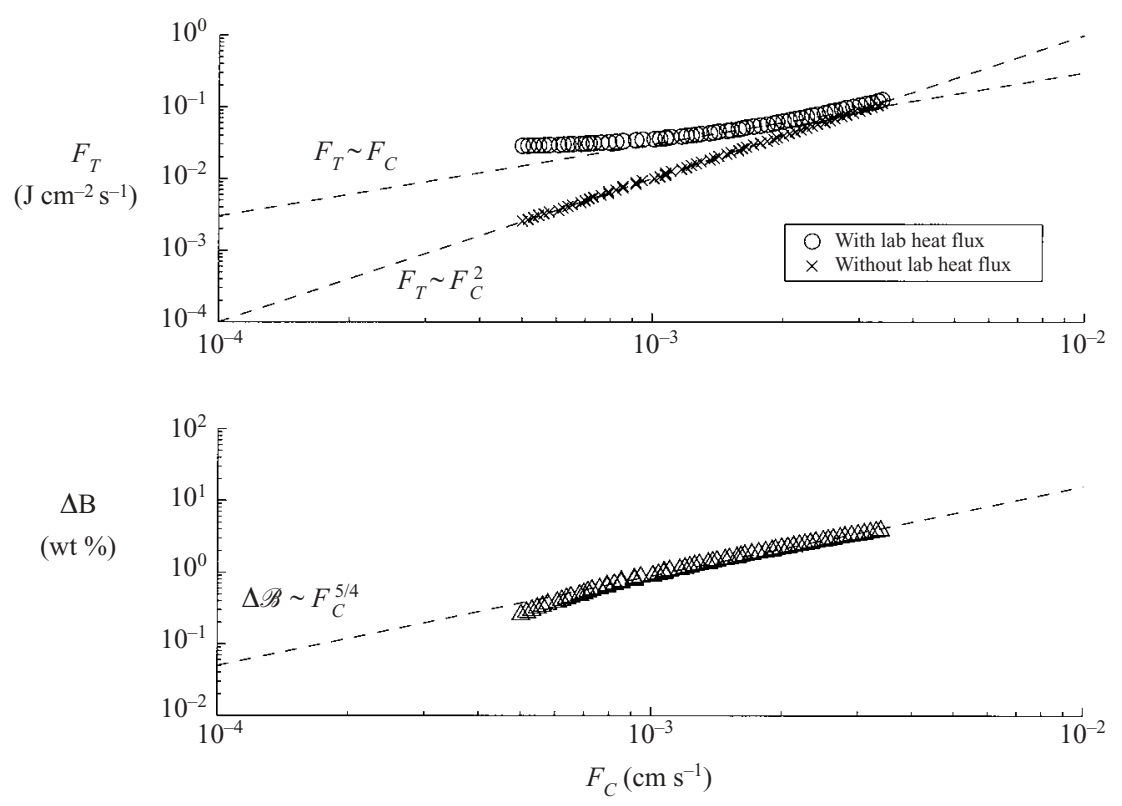

FIGURE 16. $(a)$ Heat fluxes and $(b)$ the concentration difference $\Delta \mathscr{B}$ plotted as functions of the solute flux $F_{C}$ for the first 25 hours of the simulation shown in figures 13 and 15 . We use empirical data for temperature and concentration evolution in the melt from experiment 7 . The symbols represent data from the simulation and the dashed lines are power law relationships presented for reference. The value $\Delta \mathscr{B}=\mathscr{B}_{l}-\mathscr{B}_{c}$ represents the concentration difference driving convection in the simulation.

simulation. This brief decrease in solid fraction is most likely to be caused by the rapid growth in $\phi_{c}^{A}$ at this time. The growth of $\phi_{c}^{B}$ is largest during the first five hours of the simulation as it also feels the effects of the large initial solute flux.

Another interesting feature of figure 15 is that the solid fraction of component $\mathrm{B}$ in the primary mush is larger than the solid fraction of $\mathrm{B}$ in the cotectic mush except for a brief period at the start of the simulation. One interpretation is that solid $\mathrm{KNO}_{3}$ 'melts' back into solution at the primary-cotectic mush interface. A more likely interpretation is that the primary mush lays down increasingly larger solid fractions in the cotectic mush as the solidification process proceeds. This only has a small effect on the solid fraction values in the cotectic mush because we are only considering depth-averaged values in the global conservation model. While the use of depth-averaged solid fractions is a reasonable and helpful assumption when computing the Stefan condition, care must be taken in analysing local processes such as the vertical transfer of solute at the primary-cotectic mush interface. A full local conservation model would be necessary to find the exact solutions to the solid fractions as a function of height and time, but this simple global conservation model identifies the important trends in the solid fraction evolution during the convective regime.

\subsection{Flux relationships}

In $\S 3.2$ we briefly discussed the importance of the relationship between the solute flux away from the mush-melt interface and the heat flux into this interface. Figure 16 shows the various heat and solute fluxes during the first 25 hours of 
the simulation shown in figure 13 as determined from empirical data of the evolution of temperature and salinity in the melt during experiment 7 . The data are represented by symbols, while dashed lines indicating different power law relationships are plotted for reference. A common assumption when writing the relationship between the heat flux and the solute flux is that they are linearly related so that $F_{T} \sim(\Delta T / \Delta \mathscr{B}) F_{C}$, although we note here that both $\Delta T=\left(T_{l}-T_{p}\right)$ and $\Delta \mathscr{B}=\left(\mathscr{B}_{l}-\mathscr{B}_{c}\right)$ are dependent on time. Ignoring the heat flux from the laboratory, figure 16 shows that $F_{T}$ seems to vary as the square of $F_{C}$. However, when the heat flux from the laboratory is included, the relationship between $F_{C}$ and $F_{T}$ is much closer to a linear curve. This further shows that the heat transfer between the tank and the laboratory influences the solidification process significantly.

Figure 16 also shows the relationship between the solute flux and $\Delta \mathscr{B}$, where $\Delta \mathscr{B}$ is the concentration difference that drives convection in this simulation. In $\S 3.2$ we noted that $F_{C} \sim(\Delta \mathscr{B})^{\eta}$ where $\eta$ must be less than 1 for the cotectic mush to overtake the primary mush. Here we see that the value of $\eta$ is indeed slightly less than 1 . In $\S 3.2$ we also used a simple scaling analysis to argue that $F_{C}$ is proportional to the permeability $\Pi$, which is itself dependent on $\Delta \mathscr{B}$. Applying (3.27) to the results in figure 16 we obtain

$$
\Pi \propto \frac{1}{(\Delta \mathscr{B})^{6 / 5}},
$$

which is considerably different from the relationship $\Pi \propto 1 /(\Delta \mathscr{B})^{3}$ proposed by Fowler (1985) and Worster (1992). The value of the permeability, though, depends strongly on the solid fraction, which has not been taken into account here. Clearly, further studies relating the solid fraction to the permeability and to the solute flux are necessary to develop a model that accurately describes the transfer of solute at the melt-mush interface.

\section{Conclusions}

We have presented the details of an experimental study on the solidification from below of an aqueous potassium nitrate and sodium nitrate solution in which compositional convection plays an important role in the growth dynamics. The initial concentration of the alloy in each experiment was in the $\mathrm{KNO}_{3}$ field and the tie line connected with the $\mathrm{KNO}_{3}-\mathrm{H}_{2} \mathrm{O}$ cotectic curve. The cotectic mush was both compositionally and thermally stably stratified, but buoyancy forces gave rise to convection in the primary mush and melt. Convection mixed the fluid from the upper two layers until the liquid was stably stratified and by local thermodynamic equilibrium only a single mushy layer remained. These experiments help clarify the process by which a density reversal can lead to the reduction in the number of distinct mushy layers in a solidifying alloy. These processes play a key role in governing the growth dynamics of more complex multi-component alloys.

Our experiments also identified a number of interesting features that occur at the transition from a convective to a diffusive regime. Specifically, a significant change occurs in the crystal structure and growth rate of the mushy layer. A fairly large perturbation in the temperature appears to originate at the melt-mush interface and propagates through most of the mushy layer. Once in the diffusive regime, the mushy layer adopts a dome shape with only liquid between the mush and sidewalls. A similar feature was observed by AHW, but in our experiments this shape only forms at heights above the level where the cotectic mush overtakes the primary mush. This effect may 
be due to sidewall heating from the laboratory. In general, the concentration and temperature evolution of the alloy shows good agreement with the predictions of the ternary phase diagram under the assumption of a piecewise linear liquid line of descent, and we confirm the corrections made to the $\mathrm{KNO}_{3}-\mathrm{H}_{2} \mathrm{O}$ cotectic curve made by AHW.

The global conservation model provides a relatively simple and accurate model for determining the growth rates of mushy layers although, in the convective model described here, the heat and solute fluxes must be forced by empirical data. We have presented the variation in solid fraction with initial melt concentration in a non-convecting system and compare how this changes in a convecting system where decreases in solute content in the melt are reflected by an increase in solid fractions in order to conserve solute globally. Our model identifies the pronounced effect of heating from the laboratory on the growth rates of mushy layers in a convecting system. This may be an important factor in accurately describing natural or industrial solidification processes where there is an external source of heating or cooling.

We thank Mark Hallworth for his assistance in the laboratory and Geoff Moggridge for the use of the atomic absorption spectrometer. A.F.T. was supported by a fellowship from the Keasbey Memorial Foundation. A.A. held a Daphne Jackson Fellowship supported by Lucy Cavendish College, University of Cambridge, and the Thriplow Charitable Trust.

\section{REFERENCES}

Aitta, A., Huppert, H. E. \& Worster, M. G. 2001a Solidification in ternary systems. In Interactive Dynamics of Convection and Solidification (ed. P. Ehrhard, D. S. Riley \& P. H. Steen), pp. 113122. Kluwer.

Aitta, A., Huppert, H. E. \& Worster, M. G. $2001 b$ Diffusion-controlled solidification of a ternary melt from a cooled boundary. J. Fluid Mech. 432, 201-217 (herein referred to as AHW).

Anderson, D. M. 2003 A model for diffusion-controlled solidification of ternary alloys in mushy layers. J. Fluid Mech. 483, 165-197.

Batchelor, G. K. 1974 Transport properties of two-phase materials with random structure. Annu. Rev. Fluid Mech. 6, 227-255.

Bloomfield, L. J. \& Huppert, H. E. 2003 Solidification and convection of a ternary solution cooled from the side. J. Fluid Mech. 489, 269-299.

Chen, C. F. \& Chen, F. 1991 Experimental study of directional solidification of aqueous ammonium chloride solution. J. Fluid Mech. 227, 567-586.

Copley, S. M., Giamei, A. F., Johnson, S. M. \& Hornbecker, M. F. 1970 The origin of freckles in unidirectionally solidified castings. Metall. Trans. 1, 2193-2204.

Fowler, A. C. 1985 The formation of freckles in binary alloys. IMA J. Appl. Maths 35, 159-174.

HupPERT, H. E. 1990 The fluid mechanics of solidification. J. Fluid Mech. 212, 209-240.

Huppert, H. E. \& SPARKs, R. S. J. 1980 Restrictions on the composition of mid-ocean ridge basalts: a fluid dynamical investigation. Nature 286, 46-48.

Huppert, H. E. \& Sparks, R. S. J. 1984 Double-diffusive convection due to crystallization in magmas. Annu. Rev. Earth Planet. Sci. Lett. 12, 11-37.

Huppert, H. E. \& Worster, M. G. 1985 Dynamic solidification of a binary melt. Nature 314, $703-707$.

Huppert, H. E. \& Worster, M. G. 1991 Vigorous motions in magma chambers and lava lakes. IMA Proceedings-Preprint Series 862.

Kerr, R. C., Woods, A. W., Worster, M. G. \& Huppert, H. E. 1990 a Solidification of an alloy cooled from above. Part 2. Non-equilibrium interfacial kinetics. J. Fluid Mech. 217, 331-348.

Kerr, R. C., Woods, A. W., Worster, M. G. \& Huppert, H. E. $1990 b$ Solidification of an alloy cooled from above. Part 3. Compositional stratification within the solid. J. Fluid Mech. 218, $337-354$. 
LIDE, D. R. 1997 CRC Handbook of Chemistry and Physics, 78th Edn. CRC Press.

Mullins, W. W. \& Sekerka, R. F. 1964 Stability of a planar interface during solidification of a dilute binary alloy. J. Appl. Phys. 35, 444-451.

Phillips, O. M. 1991 Flow and Reactions in Permeable Rocks. Cambridge University Press.

Sarazin, J. R. \& Hellawell, A. 1992 Studies of channel-plume convection during solidification. In Interactive Dynamics of Convection and Solidification (ed. S. H. Davis, H. E. Huppert, U. Müller \& M. G. Worster), pp. 143-145. Kluwer.

TAIT, S. \& JAUPART, C. 1992 Compositional convection in a reactive crystalline mush and melt differentiation. J. Geophys. Res. 97, B5, 6735-6756.

Thompson, A. F., Huppert, H. E. \& Worster, M. G. 2003 Appendix: A global conservation model for diffusion-controlled solidification of a ternary alloy. J. Fluid Mech. 483, 191-197.

Turner, J. S., Huppert, H. E., \& Sparks, R. S. J. 1986 Komatiites II: Experimental and theoretical investigations of post-emplacement cooling and crystallization. J. Petrol. 27, 397-437.

West, D. R. F. 1982 Ternary Equilibrium Diagrams, 2nd Edn. Chapman and Hall.

Wettlaufer, J. S., Worster, M. G. \& Huppert, H. E. 1997 Natural convection during solidification of an alloy from above with application to the evolution of sea ice. J. Fluid Mech. 344, 291-316.

Wettllaufer, J. S., Worster, M. G. \& Huppert, H. E. 2000 The solidification of leads: Theory, experiment and field observations. J. Geophys. Res. 105, 1123-1134.

Woods, A. W. \& Huppert, H. E. 1989 The growth of compositionally stratified solid above a horizontal boundary. J. Fluid Mech. 199, 29-53.

Worster, M. G. 1990 Structure of a convecting mushy layer. Appl. Mech. Rev. 43, 5, S59-S62.

Worster, M. G. 1991 Natural convection in a mushy layer. J. Fluid Mech. 224, 335-359.

Worster, M. G. 1992 The dynamics of mushy layers. In Interactive Dynamics of Convection and Solidification (ed. S. H. Davis, H. E. Huppert, U. Müller \& M. G. Worster), pp. 113-138. Kluwer.

Worster, M. G. 2000 Solidification of Fluids. In Perspectives in Fluid Dynamics (ed. G. K. Batchelor, H. K. Moffatt \& M. G. Worster), pp. 393-446. Cambridge University Press. 